\begin{tabular}{|c|c|c|c|c|c|}
\hline MUNIBE Antropologia-Arkeologia & $n^{\circ} 69$ & $211-237$ & DONOSTIA & 2018 & ISSN 1132-2217 • eISSN 2172-4555 \\
\hline
\end{tabular}

\title{
El Castru (Vigaña, Balmonte de Miranda, Asturias): un pequeño poblado fortificado de las montañas occidentales cantábricas durante la Edad del Hierro
}

\author{
El Castru (Vigaña, Balmonte de Miranda, Asturias): \\ a small hillfort in the western area of the \\ Cantabrian Mountains in the Iron Age
}

PALABRAS CLAVES: Edad del Hierro, occidente cantábrico, castro, Arqueología del Paisaje. GAKO-HITZAK: Burdin Aroa; Kantaurialdearen mendebaldea; kastroa; paisaiaren arkeologia KEY WORDS: Iron Age, western Cantabrian area, hillfort, Landscape Archaeology.

\section{David GONZÁLEZ ÁLVAREZ(1), Carlos MARÍN SUÁREZ(2), Carlotta FARCI(3), Pablo LÓPEZ GÓMEZ(4), José Antonio LÓPEZ-SÁEZ(5), Candela MARTíNEZ BARRIO(6), Marcos MARTINÓN-TORRES(7), Andrés MENÉNDEZ BLANCO ${ }^{(8)}$, Marta MORENO-GARCíA ${ }^{(9)}$, Sara NÚÑEZ DE LA FUENTE ${ }^{(10)}$, Leonor PEÑA-CHOCARRO(11), Guillem PÉREZ-JORDÁ(12), Jesús RODRÍGUEZ-HERNÁNDEZ ${ }^{(13)}$, Carlos TEJERIZO GARCÍA(14), Margarita FERNÁNDEZ MIER(15)}

\section{RESUMEN}

Este artículo presenta los datos arqueológicos recuperados en las excavaciones del poblado castreño de El Castru, en Vigaña (Balmonte de Miranda, Asturias) realizadas en 2012 y 2013. Dicho yacimiento constituye un buen ejemplo de los pequeños castros de la Edad del Hierro en las montañas del área occidental cantábrica. Por ello, el análisis de las informaciones obtenidas y su contextualización a escala regional ofrecen interesantes aportaciones al debate sobre las formas de poblamiento y subsistencia adoptadas por las comunidades del I milenio a.C. en el Noroeste ibérico.

\section{LABURPENA}

Artikulu honetan bildu ditugu El Castru (Vigaña, Balmonte de Miranda, Asturias) herrixkan 2012an eta $2013 a n$ eginiko indusketetan berreskuratutako datu arkeologikoak. Aztarnategi hori Burdin Aroan Kantaurialdeko mendebaldeko mendietan zeuden kastro txikien adibide ona da. Horregatik, eskuratutako informazioak aztertzeak eta informazio horiek eskualdeko testuinguruan kokatzeak elementu interesgarriak dakartzate Iberiar penintsulako ipar-mendebaldean K.a. I. milurtekoan zeuden komunitateek zituzten populaketa-moduei eta biziraupen-moduei buruzko eztabaidara

\section{ABSTRACT}

In this article we present and discuss the archaeological data obtained in the 2012 and 2013 excavations carried out in the hillfort of El Castru, in Vigaña (Balmonte de Miranda, Asturias, NW Iberia). The excavations have showed a long-sequence occupation of the hillfort since the Early Iron Age to the early Roman period. The site constitutes a good example of the small Iron Age hillforts of the western Cantabrian Mountains.

\footnotetext{
(1) Instituto de Ciencias del Patrimonio (Incipit), CSIC; Department of Archaeology, Durham University. e-mail: david.gonzalez-alvarez@incipit.csic.es (2) Departamento de Historia Universal, Universidad de la República (UdelaR), Uruguay. e-mail: cmarin@fhuce.edu.uy

(3) Department of Archaeology, University of Exeter. e-mail: cf440@exeter.ac.uk

(4) Departamento de Historia, Universidad de León. e-mail: plopeg02@estudiantes.unileon.es

(5) Gl Arqueobiología, Instituto de Historia, CSIC. e-mail: joseantonio.lopez@cchs.csic.es

(6) Investigadora independiente. e-mail: candelamb@gmail.com

(7) Department of Archaeology, University of Cambridge. e-mail: m.martinon-torres@arch.cam.ac.uk

(8) Área de Historia Medieval, Universidad de Oviedo. e-mail: pesicu@gmail.com

(9) GI Arqueobiología, Instituto de Historia, CSIC. e-mail: marta.moreno@cchs.csic.es

(10) Instituto Internacional de Investigaciones Prehistóricas de Cantabria (IIIPC), Universidad de Cantabria. e-mail: sara.n.delafuente@gmail.com

(11) GI Arqueobiología, Instituto de Historia, CSIC. e-mail: leonor.chocarro@csic.es

(12) GI Arqueobiología, Instituto de Historia, CSIC. e-mail: guillem.perez@csic.es

(13) Departamento de Prehistoria, Universidad Complutense de Madrid. e-mail: jesusrhav@hotmail.com

(14) Instituto de Ciencias del Patrimonio (Incipit), CSIC. e-mail: carlos.tejerizo-garcia@incipit.csic.es

(15) Área de Historia Medieval, Universidad de Oviedo. e-mail: margarita.mier@uniovi.es
} 
DAVID GONZÁLEZ ÁLVAREZ, CARLOS MARÍN SUÁREZ, CARLOTTA FARCI, PABLO LÓPEZ GÓMEZ, JOSÉ ANTONIO LÓPEZ-SÁEZ, CANDELA MARTÍNEZ BARRIO, MARCOS MARTINÓN-TORRES, ANDRÉS MENÉNDEZ BLANCO, MARTA MORENO-GARCÍA, SARA NÚÑEZ DE LA FUENTE, LEONOR PEÑA-CHOCARRO, GUILLEM PÉREZ-JORDÁ, JESÚS RODRÍGUEZ-HERNÁNDEZ, CARLOS TEJERIZO GARCÍA, MARGARITA FERNÁNDEZ MIER

For this reason, the analysis of the information collected during fieldwork and its contextualization at regional level provide us with interesting considerations for discussing about the settlement patterns and subsistence systems adopted by the I millennia BC communities in NW Iberia.

The manuscript is opened by a general overview of the hillfort, including a contextualisation of its surrounding landscape. Then, a detailed description of the six stratigraphic phases we identified during the excavations is presented, paying attention to the stratigraphic relations between different layers and structures. In addition, five radiocarbon dates are presented to build up the chronology of the site. Three huts and metallurgical production areas were explored, resulting on a significant collection of materials. The structures and layers that create each stratigraphic group are characterised considering a broad discussion about the archaeological materials that were discovered through the excavations, paying particular attention to pottery assemblages. The study and discussion of an outstanding zooarchaeological remains collection, some seeds and four pollen samples offers a relevant window to understand the anthropization of the surrounding landscape along the biography of this site. Diverse agricultural activities were developed in connection with a complex arrangement of pastoralist strategies, where we envision a growing specialization on cattle herding along the biography of this site, while agriculture is based in a wide range of complementary crops including several types of cereals. The discussion of these data considering Landscape Archaeology as our theoretical and methodological framework becomes a relevant case study in the geographical context of the western Cantabrian Mountains, where we lack this kind of approaches.

The archaeological dataset under examination in El Castru allows us to argue that the small peasant community who inhabited the hillfort along the Iron Age and the earlier decades of the Roman period could be characterised particularly by their socio-political autonomy and productive self-sufficiency. This way, we understand Iron Age social landscapes in this area under the umbrella of non-hierarchical models for social organisation, such as heterarchical societies or 'deep rural communities', following some of the interpretations recently raised by several scholars in NW Iberia.

\section{INTRODUCCIÓN}

El poblado fortificado de El Castru, en las inmediaciones de la aldea de Vigaña (Balmonte de Miranda, Asturias), constituye un buen ejemplo de los pequeños castros habitados durante la Edad del Hierro en las zonas de media montaña del área occidental cantábrica. Entre 2012 y 2013 este yacimiento fue excavado en el marco de un proyecto de investigación más amplio que pretendía construir arqueológicamente una genealogía de los paisajes agrarios de este territorio (Fernández Mier et al. 2013, 2018; Fernández Mier y González Álvarez 2013). Asumiendo la necesidad de elaborar lecturas diacrónicas de los paisajes culturales analizados, El Castru recibió la atención de nuestro equipo con el ánimo de recuperar informaciones sobre las formas productivas, sociales y culturales de las primeras comunidades humanas que, durante la Edad del Hierro, adoptaron un régimen de vida sedentario en estas montañas (González Álvarez 2016).

Este trabajo condensa la información arqueológica recuperada en dicha intervención, con una descripción detallada de la secuencia cronoestratigráfica reconocida en El Castru. Asimismo, se presentan las características arqueográficas de la cultura material recuperada en las sucesivas fases y se discuten los datos de orden productivo, doméstico y artesanal, valorando así la potencialidad de los estudios en marcha relacionados con la ocupación del poblado. Además, se contextualizan regionalmente los resultados obtenidos en este yacimiento, interpelando de este modo a las discusiones existentes en relación con las comunidades que poblaron las montañas del área occidental cantábrica en el I milenio a.C. (González Ruibal 2006-2007; Marín Suárez 2011; Maya 1989; Villa Valdés 2007).

\section{EL CASTRU, VIGAÑA}

Este poblado fortificado $[x=724129 ; y=4791930$; z=563 m (datum: ETRS89 H29)] (Fig.1) está incluido en el Inventario Arqueológico municipal como «castro» bajo la denominación La Mata el Castru (Díaz Nosty et al. 1997: ficha $n^{\circ}$ 101), aunque este topónimo no es utilizado por los vecinos de Vigaña, quienes se refieren comúnmente al lugar como El Castru. Antes de esta intervención, el yacimiento aparecía recogido en diferentes estudios (Fanjul Peraza 2005; Fernández Mier 1999; González Álvarez 2009, 2011b; Marín Suárez 2011).

El recinto se asienta sobre un crestón de roca caliza de la formación Moniello, con una franja cercana de areniscas ferruginosas de la formación Naranco al Oeste. La elevación se dispone a media ladera sobre el encajado valle del río Pigüeña, que discurre unos $240 \mathrm{~m}$ bajo la cota del yacimiento (Fig.2). El poblado se sitúa en el fondo de la pequeña vaguada de El Valle'l Pandu, al Noroeste, ocupada en la actualidad por prados cercados. Otros espacios circundantes están cubiertos de arbolado y monte bajo, tras el abandono de los campos de cultivo y los prados de siega que eran aprovechados por las familias de Vigaña hasta mediados del siglo XX, cuando comenzó un declive progresivo del régimen tradicional agrario (Fernández Mier y González Álvarez 2013). Actualmente, el yacimiento está poblado por una densa vegetación, compuesta mayoritariamente por árboles caducifolios de gran porte (castaños, robles y algún cerezo silvestre) y sotobosque asociado de avellanos, helechos y rosales silvestres.

Al inicio de nuestra intervención, el enclave mostraba derrumbes de bloques de piedra procedentes de la muralla que circunda la zona alta del castro y quizá de algunas construcciones arruinadas. El aprovechamiento agrario reciente modificó la fisonomía del antiguo poblado. Las transformaciones más importantes se produjeron en sus laderas, donde se levantó un complejo sistema de aterrazamientos con paredes de piedra y el aporte de tierra y abono. En ocasiones, estas labores reutilizaron elementos constructivos de la ruina castreña y alteraron la estratigrafía relacionada con su ocupación antigua. 


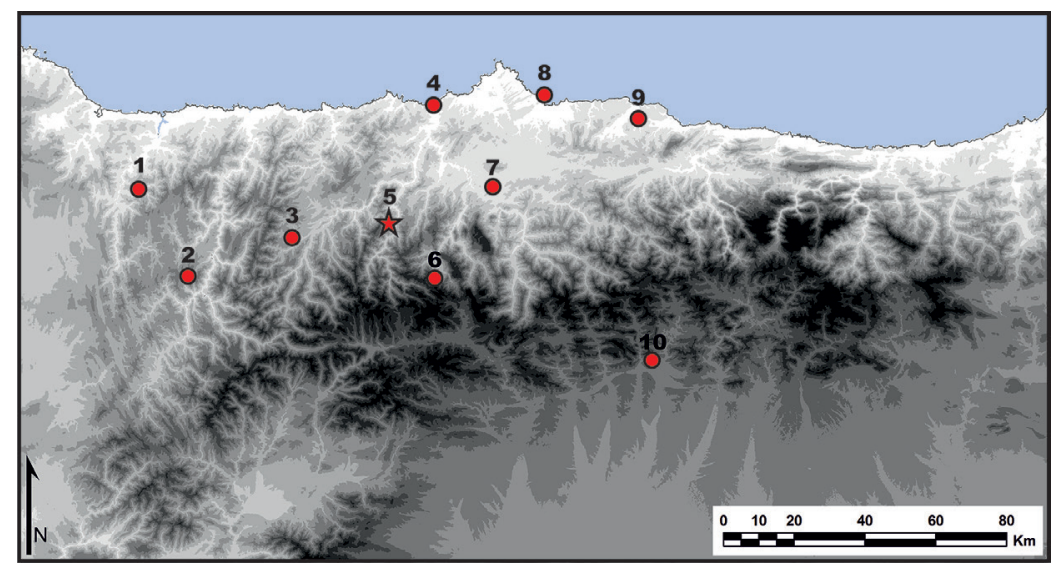

Fig. 1. Localización de El Castru en el marco del área occidental cantábrica, junto a otros castros mencionados en este trabajo: 1: Os Castros (Taramundi, Asturias); 2: El Chao Samartín (Grandas de Salime, Asturias): 3: San Lluis (Ayande, Asturias); 4: El Castillo de San Martín (Sotu'l Barcu, Asturias); 5: El Castru de Vigaña (Balmonte, Asturias); 6: La Garba (Teberga, Asturias); 7: El Castiellu de Llagú Uviéu, Asturias); 8: La Campa Torres (Xixón, Asturias); 9 : El Picu Castiellu de Moriyón (Villaviciosa, Asturias); 10: La Peña del Castro (La Ercina, León). / Location of El Castru and other hillforts mentioned in the article within the context of the western area of the Cantabrian Mountains: 1 : Os Castros (Taramundi, Asturias); 2: El Chao Samartín (Grandas de Salime, Asturias); 3: San Lluis (Ayande, Asturias) 4: El Castillo de San Martín (Sotu'l Barcu, Asturias): 5: El Castru de Vigaña (Balmonte, Asturias); 6: La Garba (Teberga, Asturias); 7: El Castiellu de Llagú (Uviéu, Asturias): 8: La Campa Torres (Xixón, Asturias); 9: El Picu Castiellu de Moriyón (Villaviciosa, Asturias); 10: La Peña del Castro (La Ercina, León).

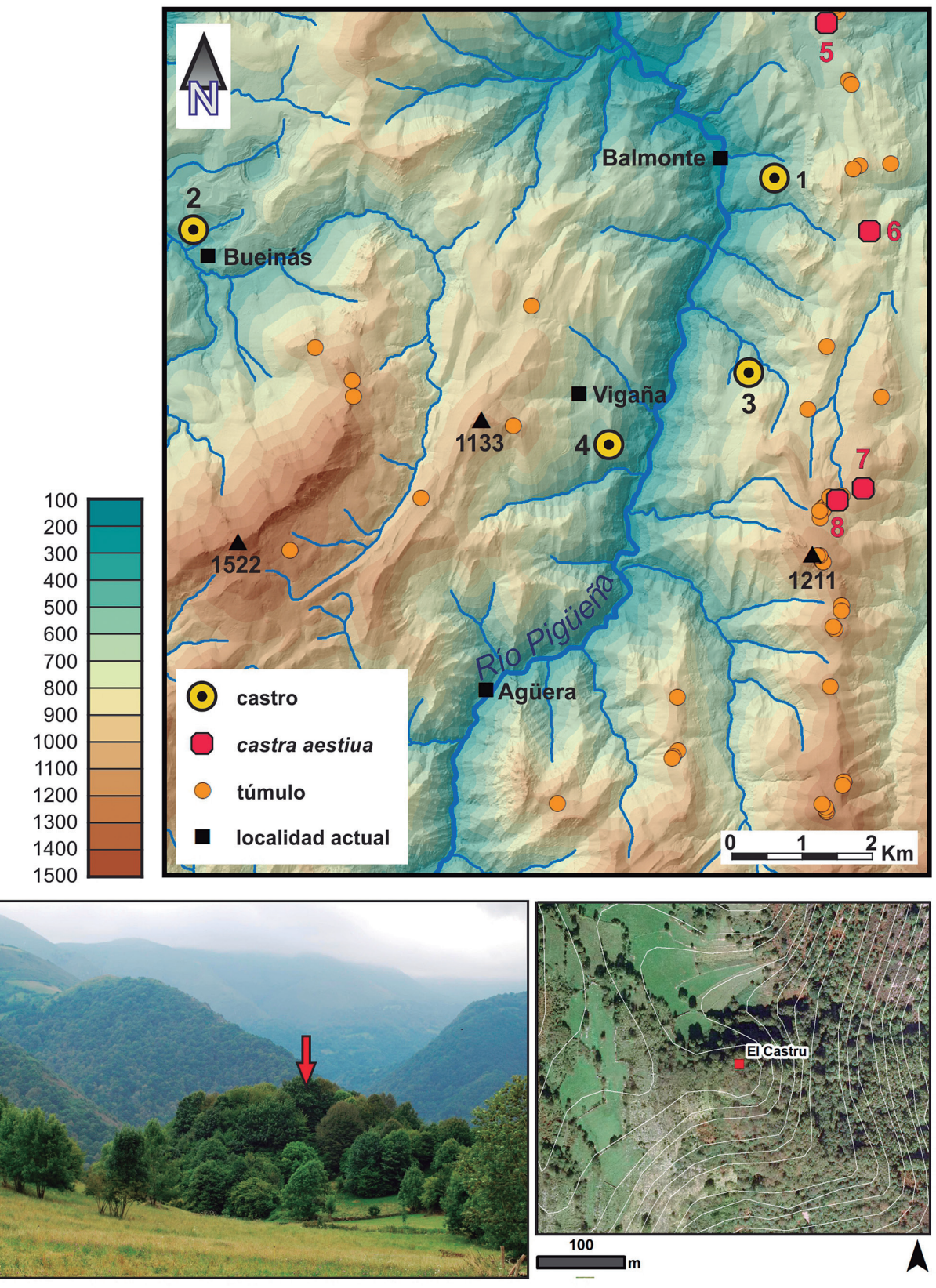

Fig. 2. Arriba: Localización del poblado analizado en la cuenca del río Pigüeña con indicación de los castros (1: El Monte la Caimada, Balmonte; 2: Penaguda, Bueinás; 3: El Castru, Ondes; 4 El Castru, Vigaña), campamentos romanos (5: Las Cruces; 6: El Llaurienzu; 7 : El Mouru; 8: Valbona) y túmulos de su entorno. Abajo: vista de El Castru de Vigaña desde El Valle'l Pandu (izquierda) y entorno sobre ortofotografía del PNOA con equidistancia de $10 \mathrm{~m}$ en las curvas de nivel (derecha). / Above: Location of the site under study within the River Pigüeña basin, showing other hillforts (1: El Monte la Caimada, Balmonte; 2: Penaguda, Bueinás; 3: El Castru, Ondes; 4: El Castru, Vigaña), Roman marching camps (5: Las Cruces; 6: El Llaurienzu; 7: El Mouru; 8: Valbona) and burial mounds in the study area. Below: a view of El Castru de Vigaña from El Valle'l Pandu (left) and the surroundings of the site in PNOA aerial image showing contour lines every 10 meters (right) 
DAVID GONZÁLEZ ÁLVAREZ, CARLOS MARÍN SUÁREZ, CARLOTTA FARCI, PABLO LÓPEZ GÓMEZ, JOSÉ ANTONIO LÓPEZ-SÁEZ, CANDELA MARTÍNEZ BARRIO, MARCOS MARTINÓN-TORRES, ANDRÉS MENÉNDEZ BLANCO, MARTA MORENO-GARCÍA, SARA NÚÑEZ DE LA FUENTE, LEONOR PEÑA-CHOCARRO, GUILLEM PÉREZ-JORDÁ, JESÚS RODRÍGUEZ-HERNÁNDEZ, CARLOS TEJERIZO GARCÍA, MARGARITA FERNÁNDEZ MIER

Como sucede en otros castros del área cantábrica (González Álvarez 2011a), las estructuras arqueológicas de El Castru no pasaron inadvertidas para los habitantes de su entorno, quienes las interpretaron en clave mítica, incorporándolas a los relatos orales del folklore tradicional. Varias personas de avanzada edad en Vigaña identificaban perfectamente las defensas amortizadas del poblado, referían la existencia de ruinas de casas, e incluso de tesoros escondidos por sus antiguos habitantes. Tales observaciones se reflejan en unos versos conservados en la aldea que señalan el lugar donde buscar un tesoro oculto por estos personajes míticos: En El Castru junto a una higuera / hay un telar de oro con su urdidera'.

La acusada pendiente de la ladera que desciende hacia el río Pigüeña limita la accesibilidad por el Este y el Sur, facilitando la defensa del emplazamiento por estos lados. Hacia el Norte y el Oeste se aprecian con nitidez dos fosos y terraplenes de disposición concéntrica que protegen la cumbre, principal zona habitable del enclave. La inspección superficial del terreno muestra cómo el trazado de la muralla se corresponde con los límites actuales del parcelario. Sobre estos, se observan acopios y amontonamientos de piedras que, probablemente, aúnan restos constructivos de la propia muralla, junto a bloques desplazados desde el interior del poblado hacia sus márgenes por los campesinos que trabajaron estos terrenos. El perímetro subcircular de la zona alta del cerro encierra un espacio intramuros no superior a las 0,15 ha. No obstante, esta reducida superficie se podría ampliar hasta las 0,25-0,30 ha de constatar la ocupación de alguna de las terrazas de la ladera septentrional del cerro, extremo no confirmado hasta la fecha. De estar ocupadas en algún caso durante la Edad del Hierro, tales estructuras habrían sufrido severas transformaciones tras la reciente construcción de las terrazas agrarias.

En definitiva, el conjunto de obras defensivas, junto al aprovechamiento de la propia orografía del terreno, contribuyen a dotar al castro de un notorio grado de monumentalidad. En general, sus características formales se corresponden con las de los poblados fortificados habitados durante la Edad del Hierro en la vertiente septentrional de las montañas occidentales cantábricas. Su reducida superficie habitable y su entorno montañoso convierten a El Castru en un buen ejemplo para explorar las formas de vida de estas pequeñas aldeas monumentalizadas de la Edad del Hierro. Además, la investigación de este poblado sirve de excelente oportunidad para llenar vacíos informativos previos en zonas de montaña del occidente cantábrico.

\section{LAS EXCAVACIONES}

Las intervenciones realizadas en El Castru se desarrollaron durante doce semanas en 2012 y 2013 en un área total de $72 \mathrm{~m}^{2}$ (Fig.3). Durante la primera campaña se exploraron dos sectores: el primero en una de las terrazas mejor conservadas de la ladera meridional del

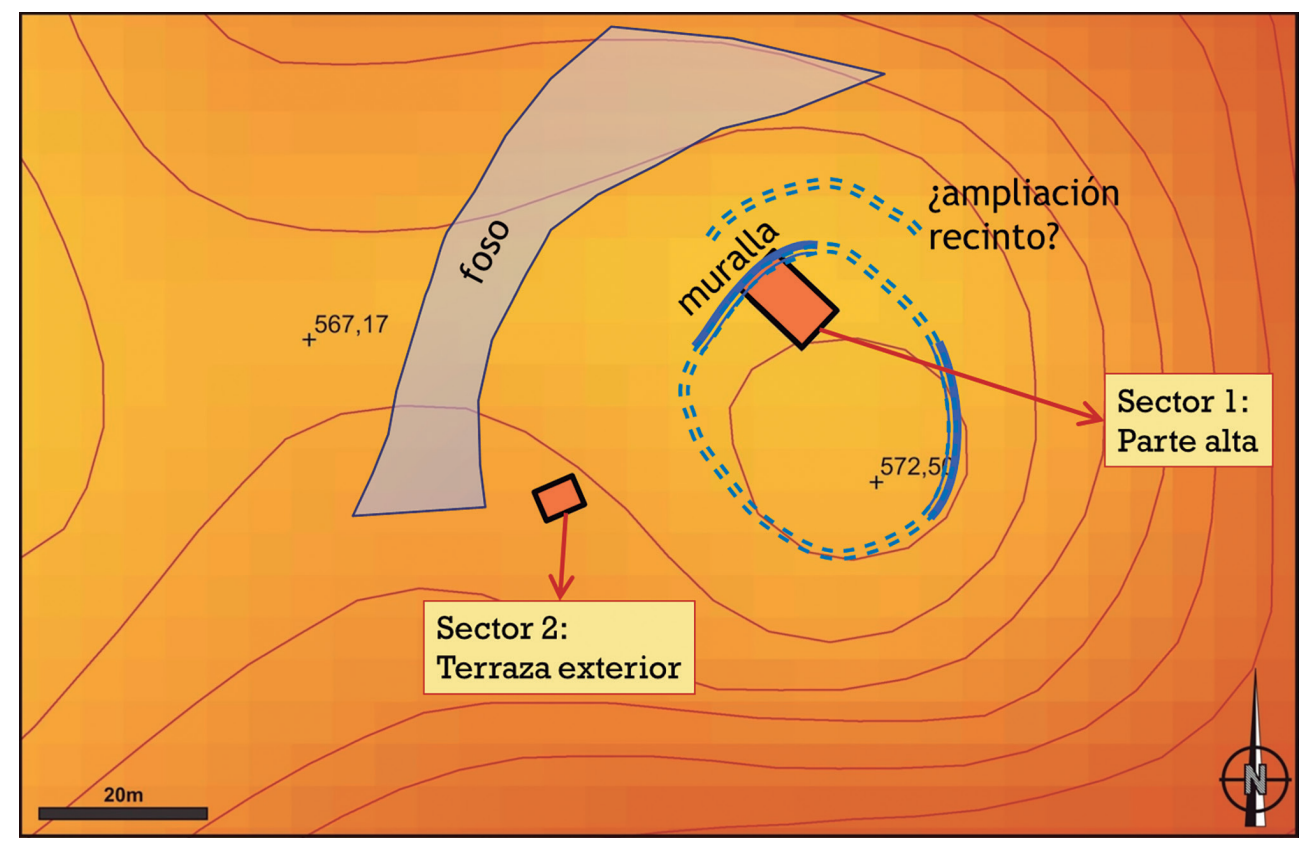

Fig. 3. Localización de las áreas intervenidas en El Castru. / Plan with the trenches that were excavated in El Castru

\footnotetext{
1 Testimonio recogido en una conversación entre las vecinas de Vigaña Justa y Emilia durante la realización del video-documental sobre la campaña de 2013: https://www.youtube.com/watch?v=IQwUDk2b7dg (último acceso: 26 de julio de 2017).
} 
cerro; y el segundo en la plataforma superior del castro, donde se centró la intervención de la segunda campaña.

Las investigaciones proporcionaron un registro arqueológico relevante para comprender la secuencia de ocupación de este asentamiento castreño y las formas de vida de sus habitantes. A continuación, describiremos de manera pormenorizada la secuencia estratigráfica por sectores a partir de las relaciones observadas durante el proceso de excavación (Harris 1991). La discusión de los resultados en un marco de trabajo interdisciplinar en el que ha participado un número amplio de especialistas permite ampliar la potencia narrativa del registro. Por su parte, la contextualización de estas informaciones y su contrastación con los resultados obtenidos en yacimientos del entorno (Camino et al. 2009; Fanjul Peraza et al. 2009; Montes López y Villa Valdés 2018; Rubio Díez y Marcos Herrán 2010) permiten densificar el conocimiento sobre las comunidades castreñas de las montañas occidentales cantábricas.

\subsection{Terraza meridional}

Asomada sobre el foso perimetral del poblado en su límite meridional, se dispone un espacio aterrazado contenido por una pared de mampuestos de caliza y cuarcita colocados en seco. En 2012 realizamos un sondeo de 3×4 m en esta área para determinar la cronología y la naturaleza constructiva del aterrazamiento, verificar la posible ocupación prerromana de este es- pacio, y comprobar si la estructura enmascaraba o se apoyaba en una muralla o aterrazamiento coetáneo a la ocupación del poblado castreño (Fig.4a).

Los niveles de la secuencia bajo la capa vegetal (UE 2001) derivan de los usos agrarios subactuales (UEs 2002, 2004 y 2007), y en ellos aparecen fragmentos de lozas y vidrios con una antigüedad que no se retrotrae más allá de los siglos XIX-XX. Estos materiales habrían llegado a El Castru como resultado de las prácticas de abonado que, atendiendo a algunos informantes locales, aportaban estiércol y basuras domésticas a estas parcelas. Así, esta zona sería un pequeño espacio de cultivo nivelado respecto a la pendiente natural mediante aportes de tierras (UE 2005) y rellenos de piedras (UEs 2006 y 2010) (Fig.4b) apoyados en el muro exterior de la terraza (UE 2003), que en algunos tramos supera 1 $\mathrm{m}$ de altura. Igualmente, la generación del espacio aterrazado implicó la remoción de paquetes de materiales de la ladera, incluyendo aportes de la ruina castreña. Destaca la UE 2010, en la que se reconocieron fragmentos de molinos giratorios, así como sillarejos semejantes a los que conforman los paramentos de la muralla o las cabañas C-1 y C-2 de la zona alta del poblado.

Bajo los niveles vinculados a la construcción de la terraza se documentaron varios depósitos (UEs 2008 y 2009) anteriores al levantamiento de dicha estructura, formados por las dinámicas naturales de arrastre en ladera. Dichos estratos rellenaban oquedades e irregularidades entre los afloramientos de bloques calizos del

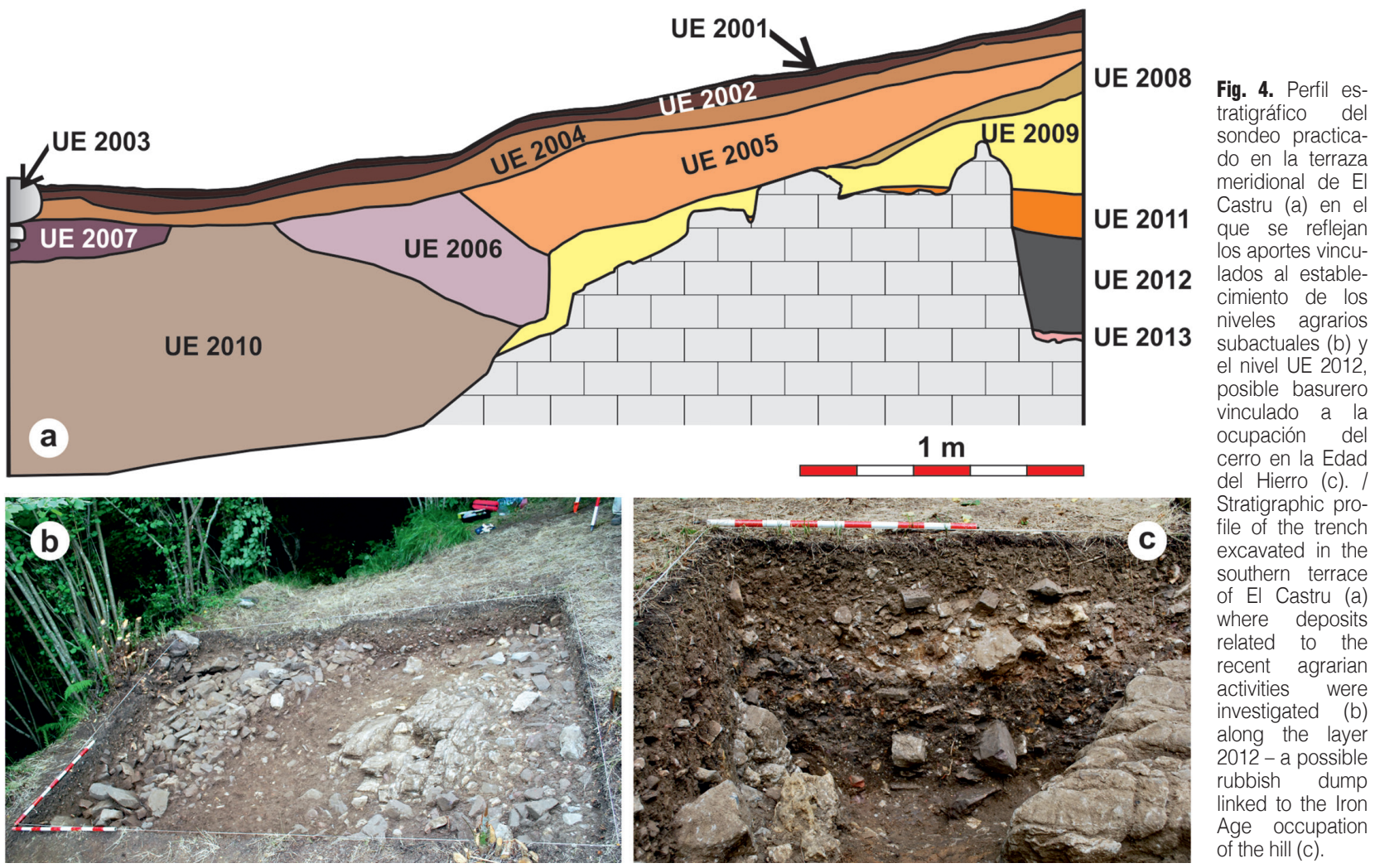


DAVID GONZÁLEZ ÁLVAREZ, CARLOS MARÍN SUÁREZ, CARLOTTA FARCI, PABLO LÓPEZ GÓMEZ, JOSÉ ANTONIO LÓPEZ-SÁEZ, CANDELA MARTÍNEZ BARRIO, MARCOS MARTINÓN-TORRES, ANDRÉS MENÉNDEZ BLANCO, MARTA MORENO-GARCÍA, SARA NÚÑEZ DE LA FUENTE, LEONOR PEÑA-CHOCARRO, GUILLEM PÉREZ-JORDÁ, JESÚS RODRÍGUEZ-HERNÁNDEZ, CARLOS TEJERIZO GARCÍA, MARGARITA FERNÁNDEZ MIER

nivel basal de la secuencia, aportando escasos materiales rodados de filiación castreña. Por ello, podemos aventurar una relativa antigüedad para dichos estratos, sin llegar a discernir si se formarían con posterioridad o en sincronía a la ocupación del poblado. Por su parte, la UE 2011 no proporcionó materiales arqueológicos, lo que unido a su composición arcillosa nos hace pensar en una unidad formada en una fase de escasa actividad antrópica en su entorno. Bajo este nivel, se identificó una unidad estratigráfica que rellenaba una de las concavidades de la roca madre. Se trata de la UE 2012 localizada en la esquina noreste del sondeo; presenta una importante cantidad de carbones y restos óseos, y constituiría probablemente un basurero cuya cronología no ha podido ser precisada (Fig.4c). El nivel de arcillas naturales UE 2013 marca el final de la secuencia.

En definitiva, este sondeo permitió confirmar que el área intervenida no muestra evidencias de su ocupación, si exceptuamos el posible basurero descrito, y que el muro que aterraza la parcela fue levantado en época contemporánea, sin que hayan sido reconocidas fases constructivas precedentes.

\subsection{Zona alta del poblado}

La segunda área intervenida se localiza en la explanada superior de El Castru. Buscábamos confirmar aquí la presencia de estructuras domésticas y caracterizar arqueográficamente su secuencia ocupacional, pues este espacio se mostraba como el más propicio para albergar las unidades domésticas de la comunidad que habitó El Castru. La intervención se inició en 2012 con un sondeo de $4 \times 4 \mathrm{~m}$ que, a la vista de los resultados positivos, fue ampliado a 6x8 m; mientras que en 2013 creció hasta los $60 \mathrm{~m}^{2}$ con un área de excavación de 6x10 m. Como resultado de ello, se reconocieron siete fases cronoestratigráficas con estructuras y restos materiales relacionados con las actividades cotidianas de los moradores de El Castru entre la Primera Edad del Hierro y las primeras décadas del siglo I d.C. durante los compases más tempranos de la dominación romana, además de niveles contemporáneos de aprovechamiento agrario. Del análisis de la información recuperada, destaca la buena conservación y las significativas concentraciones de elementos arqueobiológicos, así como las evidencias de actividades metalúrgicas.

A modo de panorámica general que sirva como referencia de la secuencia cronoestratigráfica reconocida en El Castru, se presentan a continuación las evidencias recuperadas en las siete fases sucesivas de grupos estratigráficos individualizados durante las excavaciones del yacimiento, desde las fases más antiguas a las más recientes (Fig.5). La cronología de esta secuencia ha sido acotada atendiendo a las dataciones radiocarbónicas (Tabla1) y a las características de los materiales y estructuras exhumadas.

\subsubsection{Fase 0}

La muralla del poblado marca el inicio de la secuencia crono-estratigráfica reconocida en la zona alta de El Castru. Su trazado discurre con dirección Suroeste-Noreste bordeando la zona alta del recinto por su límite exterior. Lamentablemente, esta estructura (UE 3053) sólo fue parcialmente reconocida en la esquina oeste del área excavada, desconociendo su cronología fundacional. El tramo exhumado muestra un alzado con piedras de mediano y gran tamaño sólo levemente trabajadas; muchos de estos bloques son largueros de grandes dimensiones colocados a hueso. El corazón de la estructura estaría compuesto por un relleno de cascajo y piedras de mediano tamaño, por lo que intuimos al observar la testa de la estructura. La muralla conserva varias hiladas de alzado, a cuyo paramento interior se le adosan sucesivos niveles de las fases 1, 2 y 3. Con posterioridad, esta estructura colapsaría en la fase 5 , cuando fue amortizada.

\begin{tabular}{|c|c|c|c|c|c|c|}
\hline Lab cod. & Tipo & $\begin{array}{l}\text { Material } \\
\text { datado }\end{array}$ & UE & Fecha BP & Cal BC-AD 1 sigma & Cal BC-AD 2 sigma \\
\hline Beta-377280 & AMS & Hueso & $\begin{array}{c}3080 \\
\text { (fase } 4)\end{array}$ & $2230 \pm 30$ & $\begin{array}{l}366-351 \text { cal BC }(10,1 \%) \\
300-210 \text { cal BC }(58,1 \%)\end{array}$ & $\begin{array}{l}384-339 \text { cal BC }(20,8 \%) \\
328-204 \text { cal BC }(74,6 \%)\end{array}$ \\
\hline DSH5058 & Convencional & Carbón & $\begin{array}{c}3009 \\
\text { (fase 3) }\end{array}$ & $2162 \pm 32$ & $\begin{array}{l}352-297 \text { cal BC }(35,1 \%) \\
228-221 \text { cal BC }(3,0 \%) \\
211-168 \text { cal BC }(30,0 \%)\end{array}$ & $\begin{array}{l}359-274 \text { cal BC }(41,3 \%) \\
260-108 \text { cal BC }(54,1 \%)\end{array}$ \\
\hline Fi2985 & AMS & Hueso & $\begin{array}{c}3064 \\
\text { (fase 3) }\end{array}$ & $2230 \pm 60$ & $\begin{array}{l}378-347 \text { cal BC }(14,4 \%) \\
319-206 \text { cal BC }(53,8 \%)\end{array}$ & $\begin{array}{c}403-162 \text { cal BC }(94,7 \%) \\
130-120 \text { cal BC }(0,7 \%)\end{array}$ \\
\hline Fi2952 & AMS & Hueso & $\begin{array}{c}3066 \\
\text { (fase 2) }\end{array}$ & $2365 \pm 80$ & $\begin{array}{c}738-688 \text { cal BC }(10,4 \%) \\
664-646 \text { cal BC }(3,3 \%) \\
548-366 \text { cal BC }(54,5 \%)\end{array}$ & $\begin{array}{l}768-352 \text { cal BC }(88,5 \%) \\
296-228 \text { cal BC }(6,3 \%) \\
220-212 \text { cal BC }(0,6 \%)\end{array}$ \\
\hline Fi2984 & AMS & Hueso & $\begin{array}{c}3092 \\
\text { (fase 1) }\end{array}$ & $2350 \pm 50$ & $510-379$ cal BC $(68,2 \%)$ & $\begin{array}{c}746-686 \text { cal BC }(6,7 \%) \\
666-643 \text { cal BC }(1,9 \%) \\
554-354 \text { cal BC }(82,6 \%) \\
290-232 \text { cal BC }(4,1 \%)\end{array}$ \\
\hline
\end{tabular}

Tabla 1: Dataciones radiocarbónicas obtenidas en El Castru, calibradas mediante la versión online del software OxCal v4.2.4 (Bronk-Ramsey, Lee, 2013) utilizando la curva atmosférica IntCal13 (Reimer et al., 2013). / Dataciones radiocarbónicas obtenidas en El Castru, calibradas mediante la versión online del software OxCal v4.2.4 (Bronk-Ramsey, Lee, 2013) utilizando la curva atmosférica IntCal13 (Reimer et al., 2013). 




Fig. 5. Matriz estratigráfica de la secuencia reconocida en la zona alta de El Castru. / Harris matrix with the stratigraphic sequence explored in the higher area of El Castru. 
DAVID GONZÁLEZ ÁLVAREZ, CARLOS MARÍN SUÁREZ, CARLOTTA FARCI, PABLO LÓPEZ GÓMEZ, JOSÉ ANTONIO LÓPEZ-SÁEZ, CANDELA MARTÍNEZ BARRIO, MARCOS MARTINÓN-TORRES, ANDRÉS MENÉNDEZ BLANCO, MARTA MORENO-GARCÍA, SARA NÚÑEZ DE LA FUENTE, LEONOR PEÑA-CHOCARRO, GUILLEM PÉREZ-JORDÁ, JESÚS RODRÍGUEZ-HERNÁNDEZ, CARLOS TEJERIZO GARCÍA, MARGARITA FERNÁNDEZ MIER

\subsubsection{Fase 1}

Esta fase fue reconocida en el cuadrante septentrional del área excavada, formada por un conjunto de evidencias relacionadas con la estructura C-3. El suelo UE 3092 de arcilla compactada y tenue coloración amarillenta determina la planta de la cabaña (Fig.6). Dicho nivel muestra una horizontalidad constante, consecuencia de su cuidada construcción y mantenimiento. Sus límites quedan definidos por un reborde que reflejaría el arranque de una pared no conservada compuesta por materiales perecederos. Desafortunadamente, la extensión reconocida de esta construcción se vio afectada por la apertura de las zanjas de cimentación de las cabañas de la fase 4. Por ello, únicamente reconocimos un extremo de esta estructura alargada, intuyéndose una planta alargada de extremos redondeados. Las dimensiones conservadas muestran 2,2 m de anchura y 2,75 m de longitud máxima (Fig.7). Un hueso depositado sobre el suelo de esta cabaña fue datado (Fi2984) proporcionando una cronología laxa entre los siglos VIII y III cal a.C. debido a la planicie en la curva de calibración, aunque la mayor proporción de su segmento de probabilidad se concentra entre los siglos VI-IV cal a.C., coincidiendo con la Fase Ic del fenómeno castreño en el occidente cantábrico (Jordá-Pardo et al. 2009).
La cabaña C-3 descansa sobre la roca madre que cae hacia el Noreste con una acusada pendiente en este sector, así como sobre el nivel de arcillas naturales UE 3038 que aflora puntualmente al Sur de la estructura. En aquellos puntos donde la cota de la roca madre desciende ligeramente, tal y como sucede en el extremo occidental de la cabaña, el suelo UE 3092 descansa sobre un relleno (UE 3096) que nivela y prepara el terreno para asentar esta construcción. En este sentido, la cabecera occidental de la cabaña se aproxima a la muralla en el punto donde su lienzo se retrae hacia el perfil Noroeste de la cata, sin que el suelo UE 3092 y la muralla establezcan una conexión estratigráfica directa. Debido a las limitaciones temporales de la excavación, estas relaciones fueron únicamente exploradas con un sondeo de 1×1,4 m que confirmó la posterioridad de la UE 3096 respecto a la muralla. Bajo éste se identificó a su vez el estrato UE 3102, del que desconocemos su naturaleza al no haber sido excavado. A pesar de ello, se pudo intuir su posterioridad respecto a la muralla al definir dicho estrato en planta, sin clarificar si se trata de un relleno de zanja vinculado a la fundación de la muralla u otro paquete de estratificación positiva. Ello proporciona un terminum ante quem para la construcción de la muralla, seguramente erigida en fechas previas al 600 cal a.C.

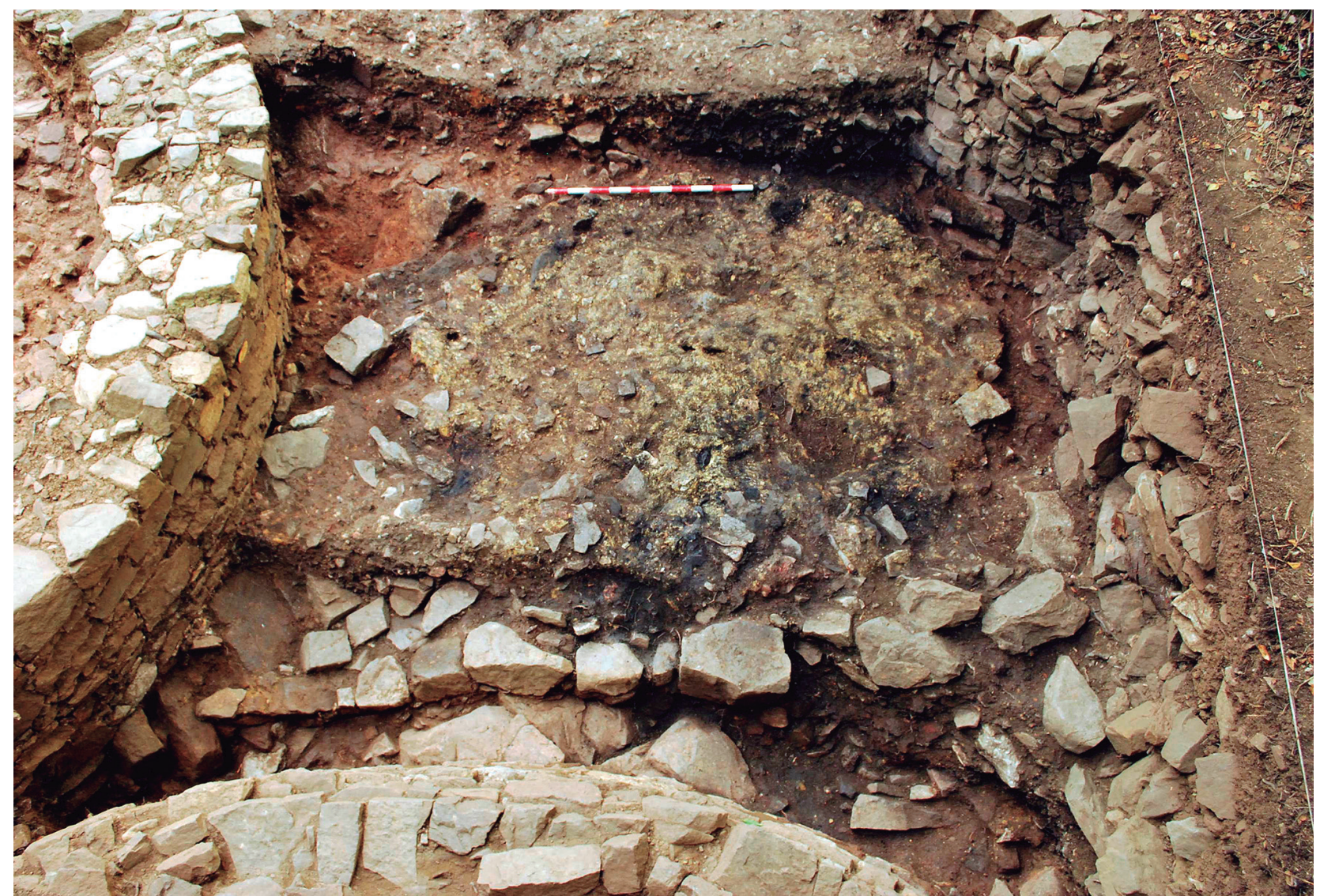

Fig. 6. Vista de la cabaña C3, definida por el suelo amarillento UE 3092. / View of hut C3, defined by the yellow soil layer 3092 


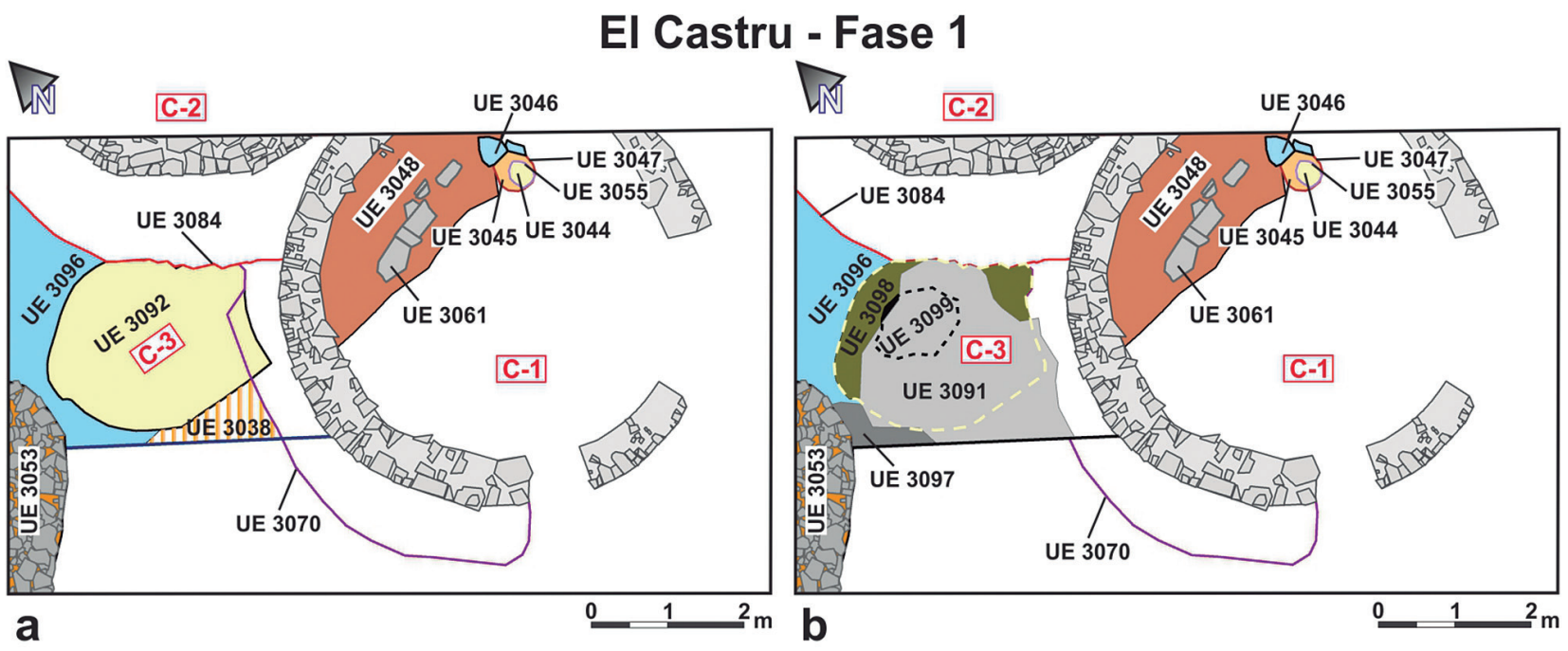

Fig. 7. Planimetría de la Fase 1, indicándose las UEs vinculadas al uso de la construcción C-3 (a) y su colapso (b). / Plan of the Phase 1, showing the layers related to the use of structure C-3 (a) and its collapse (b)

Por su parte, sobre el suelo de la cabaña C-3 se reconocieron diferentes niveles relacionados con su uso y amortización. Directamente sobre la UE 3092, y con una extensión coincidente, se documentó el estrato UE 3098, compuesto por tierra suelta ennegrecida y abundantes carbones. Este nivel muestra un grosor reducido de entre 3-5 cm, con presencia de restos faunísticos muy fragmentados. Su topografía y sus características sugieren que sería el último nivel de uso de la construcción. Sobre este horizonte, caerían posteriormente materiales procedentes de las paredes y la cubierta de esta cabaña, diferenciándose concentraciones como la UE 3099 con restos quemados de piezas lígneas de buen porte que indicarían la probable contribución del fuego a su colapso. Por encima, el estrato UE 3091 es un extenso nivel de tierra suelta y matriz ennegrecida con abundantes carbones y piedras planas de tamaño medio que constituiría el derrumbe de la cubierta vegetal. La marcada horizontalidad de la mayoría de estas lajas -que podrían haber tenido una función sustentante de los componentes vegetales de la cubierta- y su disposición en arco coincidente con el borde exterior del suelo Norte/Noreste de la cabaña apoyarían tal hipótesis. El techo de la fase 1 está delimitado por el estrato UE 3097 de tierra suelta con gran presencia de carbones y restos de madera quemada.

Además de los niveles constructivos identificados en la esquina norte de la cata, varios estratos asimilables a la fase 1 fueron localizados bajo los rellenos de nivelación de la fase 4 al interior de C-1. En este espacio, el posible suelo o nivel de preparación UE 3048 se adosa a un rebaje rectilíneo en la roca madre. Dicho estrato muestra una cota superior equivalente al suelo de la estructura C-3, aunque sus características no encuentran un paralelo claro en las unidades descritas para el área exterior de la esquina norte, como la consistencia, el característico color amarillo del suelo UE
3092, o la inexistencia aquí de evidencias asimilables al desplome de la techumbre de C-3. En paralelo al mencionado rebaje, el murete UE 3061 compuesto por grandes bloques careados corre con una dirección Este-Oeste que concuerda con el límite meridional de C-3. De funcionar conectado a aquella cabaña, y considerando que no identificamos ningún bloque constructivo relacionado con el límite del suelo UE 3092, debemos pensar en una función estructural independiente para estos grandes bloques, como podría ser el solado de una entrada. Por último, continuando grosso modo la misma alineación aparece un gran hoyo de poste relacionable con algún tipo de construcción, delimitado por el corte de planta circular UE 3047, de 50-60 cm de diámetro y $30 \mathrm{~cm}$ de profundidad conservada. En su interior, varias piedras (UE 3046) funcionarían como calzos para sujetar un gran poste, mientras que el relleno UE 3045 estaba a su vez cortado por otro hoyo menor UE 3055 relleno por la UE 3044. Este grupo estratigráfico habría alojado un poste con el porte suficiente para sostener una estructura de cierta envergadura. Considerando su alineación respecto al entalle que acoge el nivel de uso UE 3048 y el murete UE 3061, no sería descabellado plantear que este conjunto de evidencias formase parte de alguna construcción o nivel de ocupación perteneciente a la fase 1, quizá formando parte incluso de la ya descrita cabaña C-3. No obstante, existen ciertas dudas para establecer tal relación, dislocada físicamente por la apertura de la zanja de cimentación UE 3070 para construir la cabaña C-1 de la fase 4.

\subsubsection{Fase 2}

Los niveles que conforman la fase 2 fueron reconocidos en la esquina norte de la cata (Fig.8a). Esta fase está relacionada con actividades artesanales, si bien no se ha podido determinar el tipo de labores de- 
DAVID GONZÁLEZ ÁLVAREZ, CARLOS MARÍN SUÁREZ, CARLOTTA FARCI, PABLO LÓPEZ GÓMEZ, JOSÉ ANTONIO LÓPEZ-SÁEZ, CANDELA MARTÍNEZ BARRIO, MARCOS MARTINÓN-TORRES, ANDRÉS MENÉNDEZ BLANCO, MARTA MORENO-GARCÍA, SARA NÚÑEZ DE LA FUENTE, LEONOR PEÑA-CHOCARRO, GUILLEM PÉREZ-JORDÁ, JESÚS RODRÍGUEZ-HERNÁNDEZ, CARLOS TEJERIZO GARCÍA, MARGARITA FERNÁNDEZ MIER

sarrolladas, aunque es probable que suponga un antecedente no muy lejano en el tiempo a la instalación de las estructuras metalúrgicas de la siguiente fase. El conjunto amortiza niveles domésticos de la fase 1.

El estrato UE 3054 marca el inicio de la fase. Este paquete heterogéneo que se apoya en la muralla está caracterizado por la presencia de concentraciones de carbones y la ausencia de materiales broncíneos, así como por la abundancia de restos faunísticos. Sobre este horizonte se identificó la cubeta $\mathrm{Cu}-3$, probablemente alterada por la construcción de la cubeta Cu-1 en la fase 3 (Fig.8b). La UE 3071 consolida la forma de la cubeta Cu-3 como un arco de arcilla compactada construido sobre piedras de pequeño/mediano tamaño de las pertenecientes a la infrayacente UE 3054. En su interior se documentó un primer relleno UE 3076 con abundantes carbones, resultado de procesos de combustión. Sobre éste, otro relleno (UE 3074) está formado por sedimento blanquecino de textura granulada y que, a la espera de futuros análisis de su composición, podría ser un subproducto de la calcificación parcial de calizas sometidas a altas temperaturas. La función de esta pequeña cubeta resulta incierta. Un aspecto revelador en su interpretación es la inexistencia o muy baja frecuencia de aparición de materiales metálicos, lo cual contrasta con los estratos de la posterior fase 3. Las evidencias disponibles advierten por tanto del desarrollo de actividades que conllevaron la presencia de calor, y que no supondrían la reducción de minerales o la fusión de metales. La UE 3069, en la que se observaba igualmente una abundante presencia de piedras calizas, amortiza esta fase y da paso a la fase 3 de la secuencia.

Además de la cubeta Cu-3, en esta fase aparece el estrato UE 3066 de tierra suelta y abundantes carbones que describe una planta ovalada sobre la UE 3054. Constituiría el fondo de una cubeta prácticamente arrasada de la que sólo se conservó una delgada capa de sección aplanada sobre la UE 3054. En su excavación se recuperaron abundantes restos óseos de fauna, y de nuevo estuvieron ausentes los materiales metalúrgicos. El análisis de un fragmento óseo recuperado en su relleno proporcionó una datación (Fi2952) con una amplia horquilla derivada de la denominada meseta de la Edad del Hierro en la curva de calibración, y que se extiende entre los siglos VIII y III cal. a.C., aunque el mayor porcentaje de probabilidad se concentra en el segmento VIII-IV cal a.C. Con los datos disponibles no resulta posible determinar su función, aunque es posible pensar en los restos de una estructura de combustión.

\subsubsection{Fase 3}

En esta fase se reconocen dos cubetas metalúrgicas para la reducción de cobre (Cu-1 y Cu-2) en el cuadrante oeste del área excavada y varios niveles relacionados con la producción de piezas metálicas con base cobre durante la Segunda Edad del Hierro. Este conjunto sería posteriormente amortizado por estratos asignables a la fase 5 , mientras que las zanjas de cimentación de la fase 4 cortaron algunos de estos niveles. Por ello, muchos materiales vinculados con las actividades metalúrgicas de esta fase -escorias, gotitas de fundición, fragmentos de crisoles, etc.- fueron incorporados a los procesos de estratificación de fases posteriores.

La cubeta Cu-1 está pegada al interior de la muralla en una posición marginal del poblado análoga a otros espacios metalúrgicos reconocidos para la Edad del Hierro del occidente cantábrico (Fanjul Peraza y Marín Suárez 2006; Jordá-Pardo et al. 2011; Maya y Cuesta 2001: 91-97; Villa Valdés 2004). Se trata de una estructura de combustión para la reducción de cobre construida con una arcilla amarilla endurecida UE 3007 (Fig.9a). Conserva las dimensiones de su planta ovalada y la sección basal de su cubeta interior, reconociéndose un relleno UE 3009 relacionable con la amortización del horno una vez éste dejó de funcionar. De este nivel se obtuvo una datación (DSH5058) entre los siglos IV-II cal a.C. que marca una fecha ante quem para el funciona-

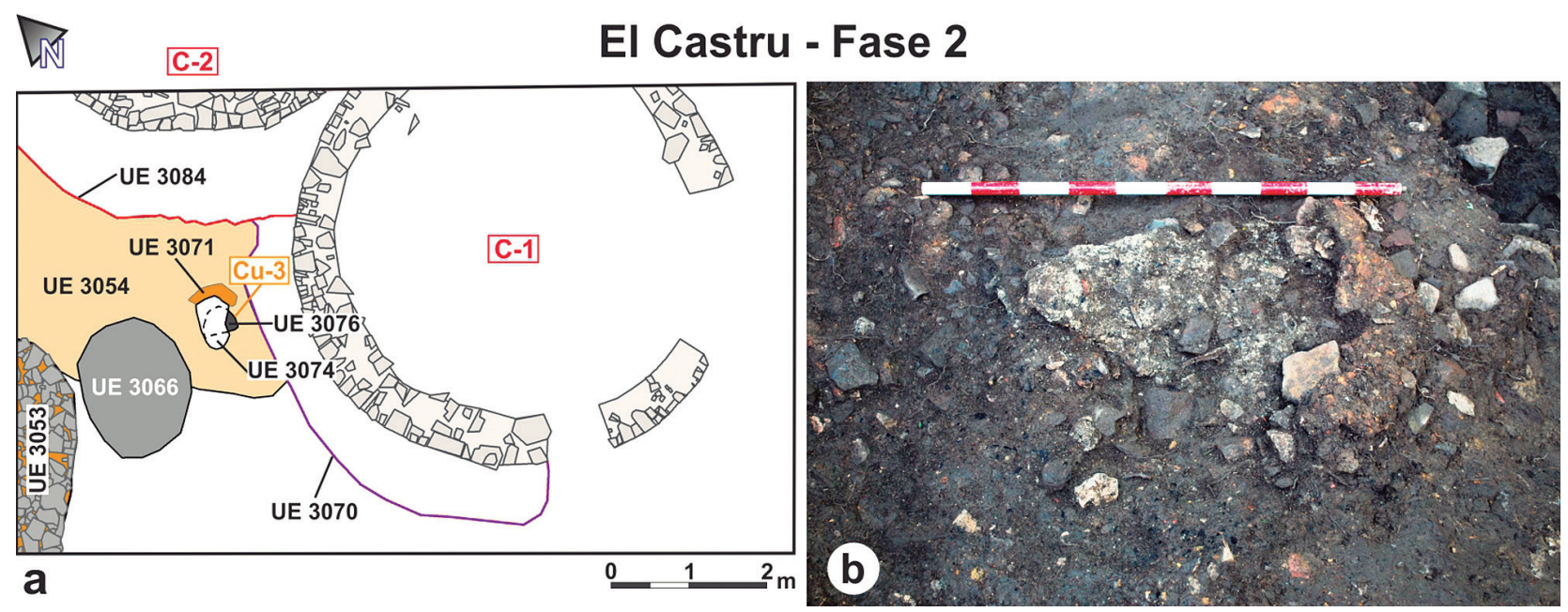

Fig. 8. Planta de la Fase 2 (a) y vista en detalle de la estructura Cu-3 (b). / Plan of the Phase 2 (a) and detailed view of structure Cu-3 (b). 
miento de la cubeta. Entre los materiales recuperados en este nivel, sobresalen los elementos relacionados con las actividades metalúrgicas, así como materiales de procedencia doméstica que se habrían depositado aquí tras el abandono del espacio artesanal.

La estructura Cu-1 fue emplazada en una zona en la que existían niveles y estructuras previas, y en la que además arranca la pendiente que cae hacia el Noreste. Por ello, fue necesario para sus constructores acondicionar y nivelar esta área. Así, la cubeta descansa sobre rellenos (UEs 3064 y 3081) y elementos constructivos como los arcos de grandes bloques de piedras UEs 3065 y 3086 que garantizaban su contención (Fig.9b). Singularmente, la UE 3064 ofreció gran cantidad de restos óseos de fauna, así como piezas de bronce. Entre ellas destacan una cabeza de fíbula de torrecilla, aunque no aparecían gotitas de fundición, tan abundantes en los estratos posteriores. Por ello, podría
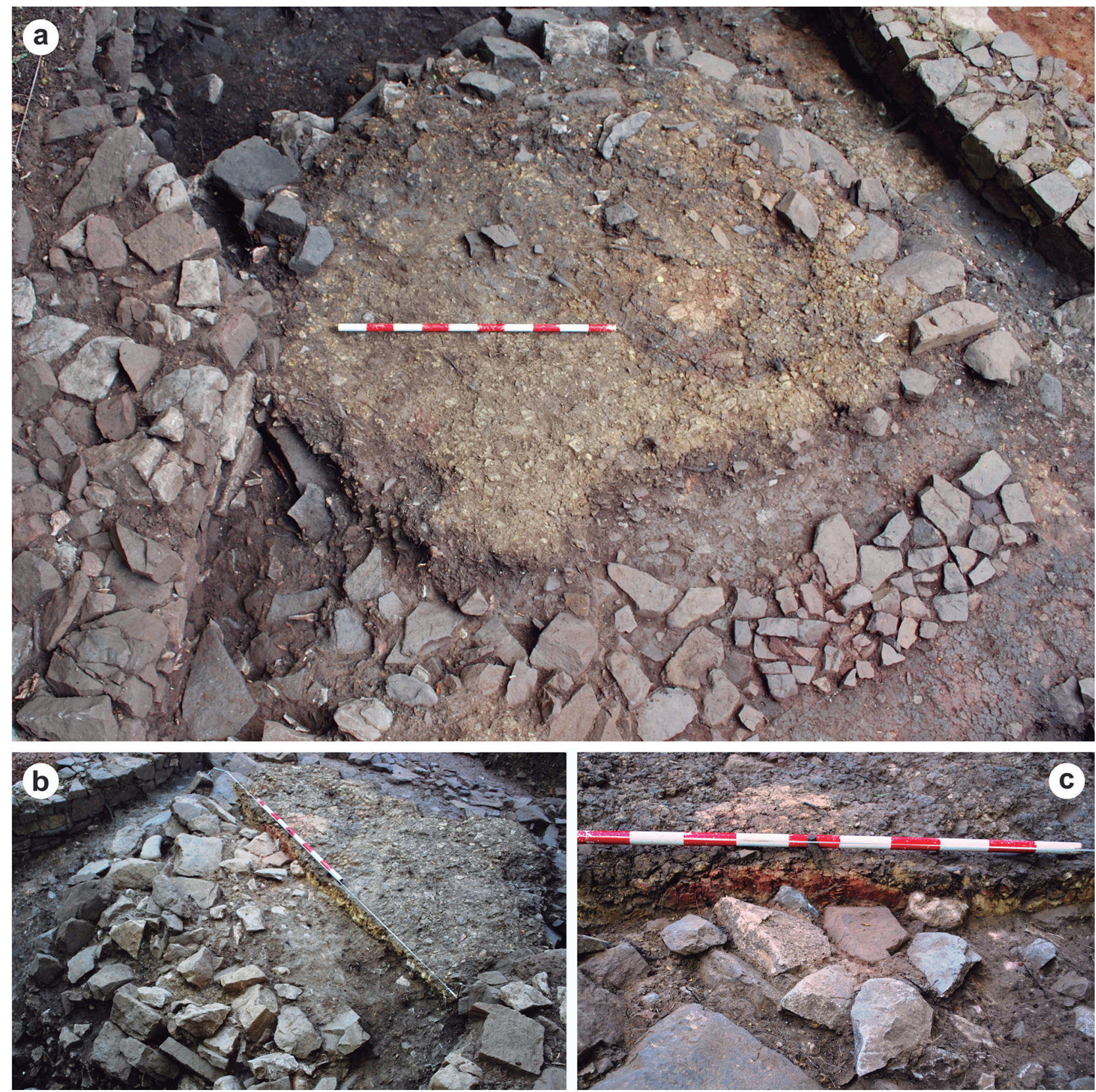

Fig. 9. Cubeta metalúrgica Cu-1: La estructura está definida por un estrato constructivo UE 3007 de arcilla amarilla y se localiza junto a la muralla castreña sobre el suelo UE 3012 de arcilla roijza (a). Para elevar la cubeta sobre la pendiente del sector, se alinearon bloques de piedra (UE 3065 y 3086 ) que contenían la estructura (b). En la zona central de la cubeta, una parrilla de piedras planas UE 3063 determina el espacio donde se alcanzaban mayores temperaturas (c). / Metallurgic structure Cu-1: the constructive layer 3007 made out of yellow clays defines the structure and it is located by the wall of the hillfort, above the red clays layer 3012 (a). Aiming to elevate the metallurgic structure in this area, some stones (layers 3065 and 3085) were aligned to contain the construction (b). In the central area of the metallurgic pit, a stone platform (layer 3063) points out the space where the highest temperatures were reached (c). 
DAVID GONZÁLEZ ÁLVAREZ, CARLOS MARÍN SUÁREZ, CARLOTTA FARCI, PABLO LÓPEZ GÓMEZ, JOSÉ ANTONIO LÓPEZ-SÁEZ, CANDELA MARTÍNEZ BARRIO, MARCOS MARTINÓN-TORRES, ANDRÉS MENÉNDEZ BLANCO, MARTA MORENO-GARCÍA, SARA NÚÑEZ DE LA FUENTE, LEONOR PEÑA-CHOCARRO, GUILLEM PÉREZ-JORDÁ, JESÚS RODRÍGUEZ-HERNÁNDEZ, CARLOS TEJERIZO GARCÍA, MARGARITA FERNÁNDEZ MIER

determinarse su origen en aportes de residuos domésticos desconectados de la actividad metalúrgica. La datación de un hueso recuperado en este estrato ofrece una fecha (Fi2985) post quem para el funcionamiento de esta estructura en la Segunda Edad del Hierro. Por su parte, una plataforma de lajas planas (UE 3063) genera una «parrilla» en el centro de la concavidad de Cu-1 que constituiría el ámbito central para las labores metalúrgicas y donde se alcanzarían las temperaturas más altas de la cubeta. Como muestra de ello, la arcilla UE 3010 que recubre estas lajas aparece rubefactada, adquiriendo una viva coloración anaranjada y un alto grado de compactación (Fig.9c).

Al exterior de esta estructura se generó una importante colada con desechos derivados de las actividades metalúrgicas que cae hacia el Norte-Noreste, siguiendo la pendiente de la ladera (Fig.10). Con una potencia creciente, desde unos pocos centímetros al borde de la cubeta, hasta $50 \mathrm{~cm}$ en el sector septentrio- nal de su extensión, este estrato UE 3011 está caracterizado por la abundancia de carbones y la presencia de grandes piedras que buzan en diferentes direcciones. Algunos de estos bloques formarían parte de los derrumbes UEs 3020 y 3026 de la fase 5, clavados en el nivel subyacente, mientras que otros habrían sido aportados durante la formación del basurero. Además de materiales derivados de las actividades metalúrgicas, se reconocen también desechos domésticos provenientes de áreas del poblado habitadas mientras funcionaba este taller. La excavación de la UE 3011 ofreció una alta densidad de hallazgos, con restos de fauna, fragmentos cerámicos, elementos metálicos, escorias y crisoles. La homogeneidad de su matriz ennegrecida, con abundante presencia de carbones, imposibilitó la distinción de subniveles, aunque es probable que estos existiesen como consecuencia de sucesivas coladas formadas por las limpiezas de la cubeta y vertidos de basura doméstica.

\section{El Castru - Fase 3}

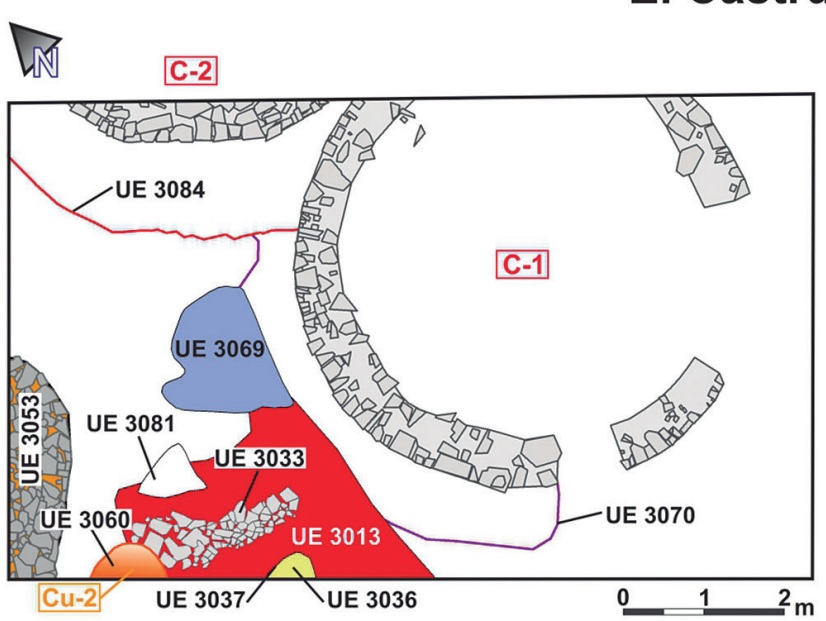

a

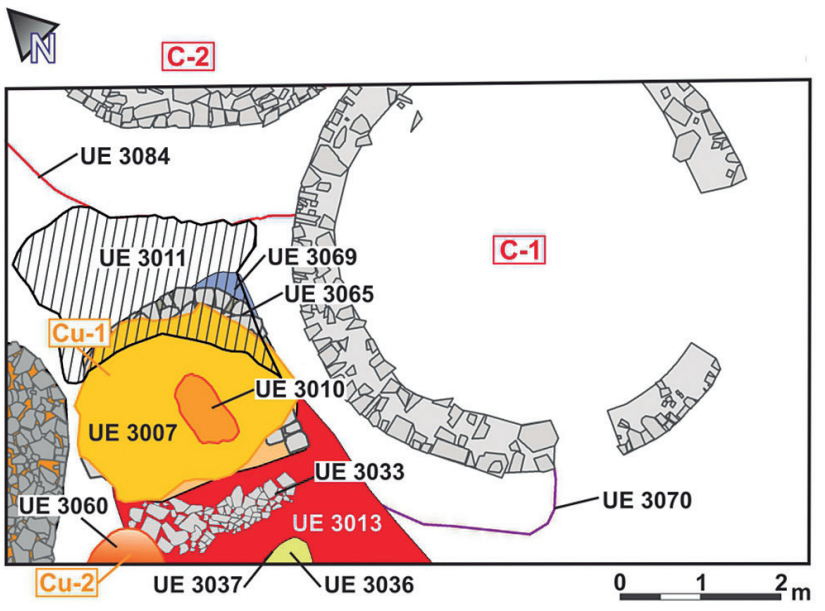

C

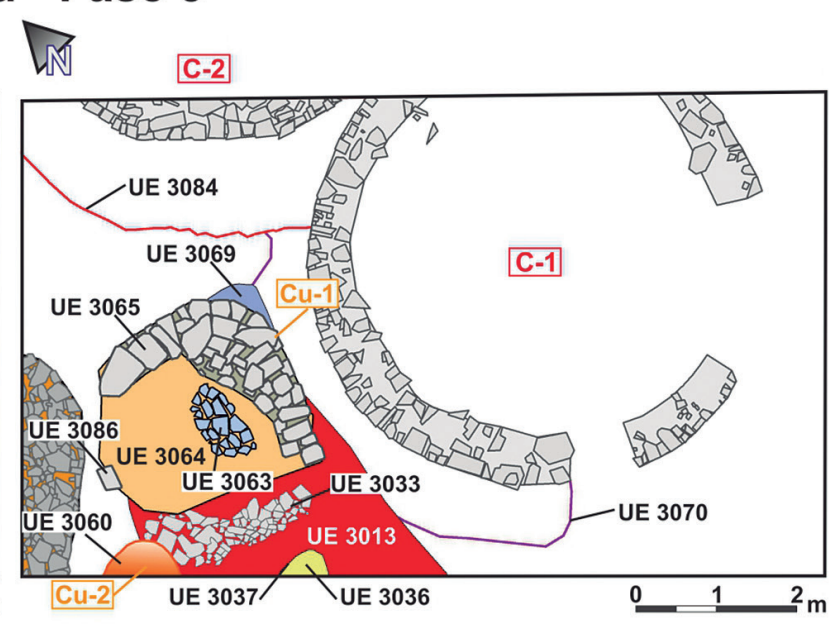

b

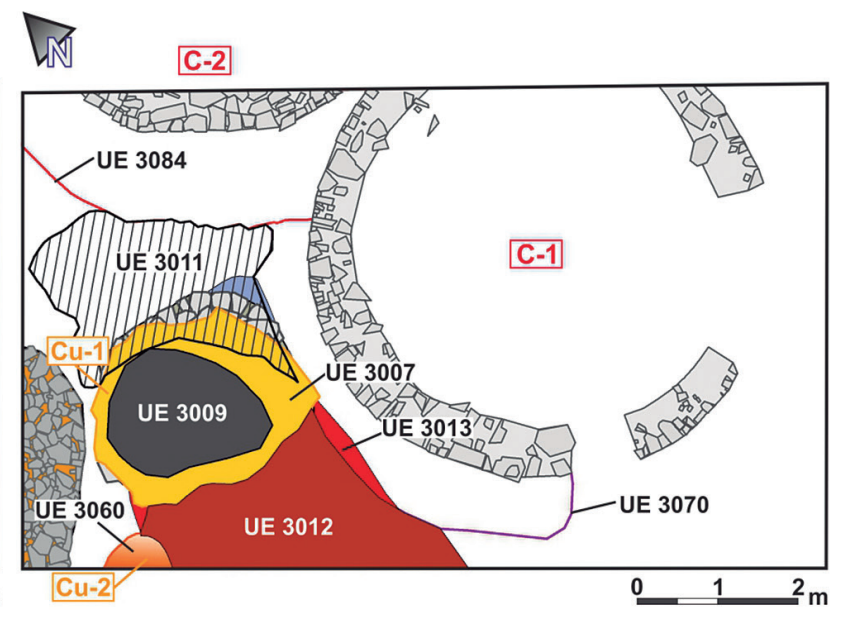

d

Fig. 10. Planimetría con los diferentes grupos estratigráficos que forman la Fase 3 de la secuencia en relación con las estructuras Cu-1 y Cu-2. / Plan with the different stratigraphic groups of Phase 3 in relation to structures Cu-1 and Cu-2 
La cubeta Cu-2 aparece en la misma zona, aunque su unidad constructiva UE 3060 sólo fue reconocida en planta desde el perfil suroeste de la cata. Muestra unas características similares a la UE 3007 de la cubeta Cu1, lo que unido a su situación sobre el estrato UE 3013 hace probable un funcionamiento sincrónico de ambas. Las dos estructuras metalúrgicas se asientan sobre un nivel de arcilla rojiza endurecida (UE 3013) con evidentes muestras de rubefacción. Este estrato genera la superficie sobre la cual se transitaría durante el funcionamiento de ambas cubetas metalúrgicas en este espacio pegado a la cara interna de la muralla. Sobre este horizonte, aparecen estratos como el encachado de piedra UE 3033, que acondicionaría parte de este espacio para el tránsito. Sobre las UEs 3013 y 3033 se formó el nivel de uso UE 3012 con gran cantidad de carbones y materiales vinculados a la producción metalúrgica, siendo abundantes las gotitas de fundición. También se reconoció un hoyo UE 3037 excavado en el nivel UE 3013, que podría haber sujetado algún poste de estructuras lígneas vinculables al área de actividad metalúrgica (Fig.11).

Bajo la cubeta Cu-1 se identificó el estrato terroso UE 3069, caracterizado por la presencia de pellas arcillosas amarillentas y fragmentos de piedra caliza, algunas descompuestas en granos de modo semejante a lo observado en la fase anterior. En su excavación se recuperaron abundantes restos faunísticos y elementos de hierro y bronce. Este depósito constituiría un nivel de preparación para la instalación de los estratos que asientan la cubeta Cu-1, al tiempo que sella las estructuras previas de la fase 2 .

\subsubsection{Fase 4}

Esta fase incluye grupos estratigráficos relacionados con la construcción y uso de las cabañas C-1 y
C-2. El levantamiento de ambas estructuras conllevó la apertura de zanjas de cimentación, así como el vertido de rellenos y niveles de acondicionamiento del espacio ocupado por construcciones precedentes ya amortizadas (Fig.12). Los materiales recuperados en estos estratos, así como las dataciones radiocarbónicas, sitúan esta fase en la Segunda Edad del Hierro.

La cabaña C-1 fue reconocida prácticamente en toda su extensión, aunque un pequeño tramo de su zócalo quedó fuera del área de excavación hacia el perfil noreste. Dicha construcción está definida por el zócalo UE 3008, construido con lajas de cuarcita y algunas calizas. Muestra un trazado circular coincidente con patrones observados en la arquitectura doméstica de otros castros del entorno (Ayán Vila 2012; Marín Suárez 2011). La cabaña cuenta con unos $4,5 \mathrm{~m}$ de diámetro interior que generarían una superficie aproximada de 17 $\mathrm{m}^{2}$, aunque de incluir la anchura del propio zócalo -que alcanza los $70 \mathrm{~cm}$ en sus tramos más gruesos- el diámetro de la construcción alcanzaría 5,75 m (Fig.13a). Mientras el paramento exterior del zócalo fue construido con sumo cuidado (Fig.13c), la estructura no ofrece una cara interna definida, pues se iría levantando conforme se elevaba su espacio interior con rellenos de nivelación y preparado para el suelo (UEs 3014 y 3032). De este modo se configuró una especie de «tambor» sobre el que la cabaña se alzaría con postes de madera y paredes de entretejido vegetal y barro. La altura del zócalo es variable, adaptada a la pendiente natural del terreno, y una capa de arcilla amarilla (UE 3016) cubre completamente su cara externa y la superficie horizontal sobre su testa. Lamentablemente, el interior de la cabaña fue arrasado en la fase 6 , por lo que no se conservaron suelos asociados ni se detectaron los hoyos de poste que soportarían la cubierta. Además,

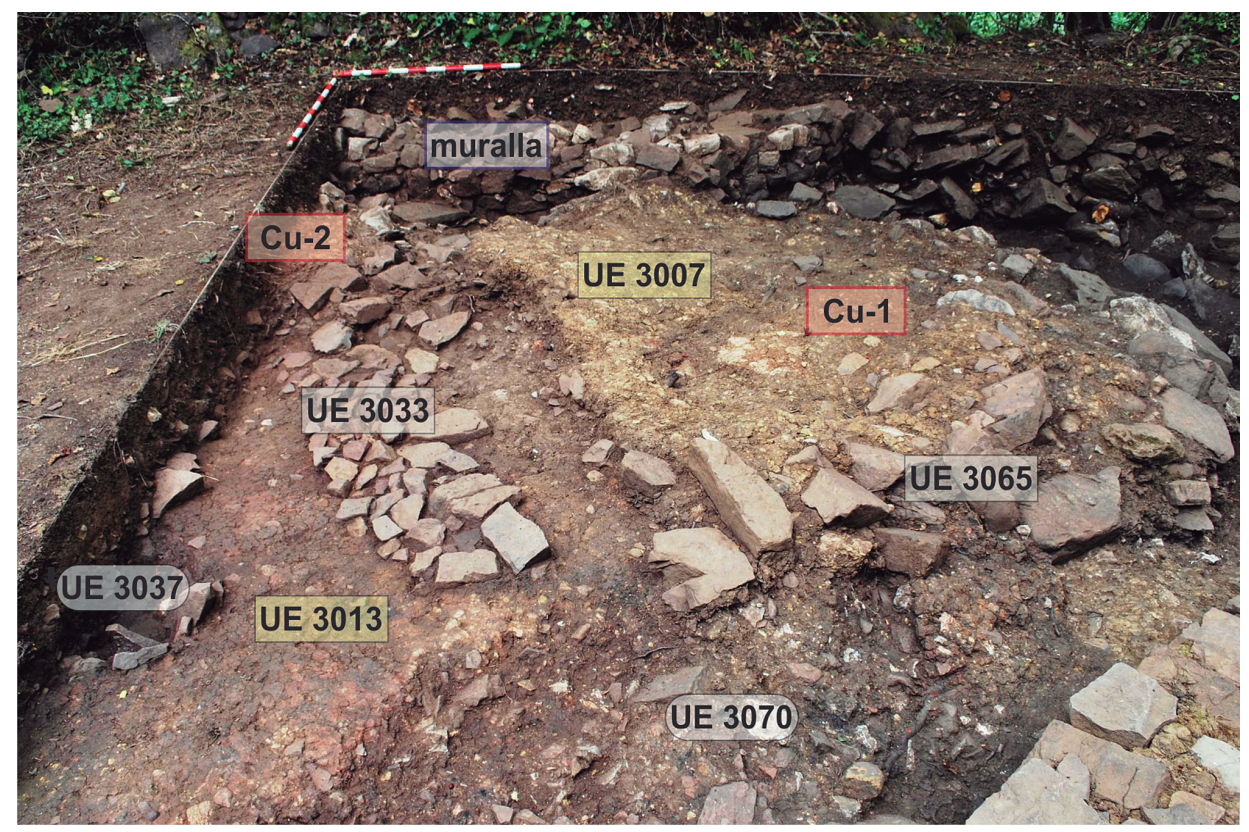

Fig. 11. Vista general del área metalúrgica de la Fase 3, con las cubetas $\mathrm{Cu}-1, \mathrm{Cu}-2$ y los estratos asociados. $/$ General view of the metallurgical area in Phase 3 with the structures $\mathrm{Cu}-1$, $\mathrm{Cu}-2$ and their associated layers. 
DAVID GONZÁLEZ ÁLVAREZ, CARLOS MARÍN SUÁREZ, CARLOTTA FARCI, PABLO LÓPEZ GÓMEZ, JOSÉ ANTONIO LÓPEZ-SÁEZ, CANDELA MARTÍNEZ BARRIO, MARCOS MARTINÓN-TORRES, ANDRÉS MENÉNDEZ BLANCO, MARTA MORENO-GARCÍA, SARA NÚÑEZ DE LA FUENTE, LEONOR PEÑA-CHOCARRO, GUILLEM PÉREZ-JORDÁ, JESÚS RODRÍGUEZ-HERNÁNDEZ, CARLOS TEJERIZO GARCÍA, MARGARITA FERNÁNDEZ MIER

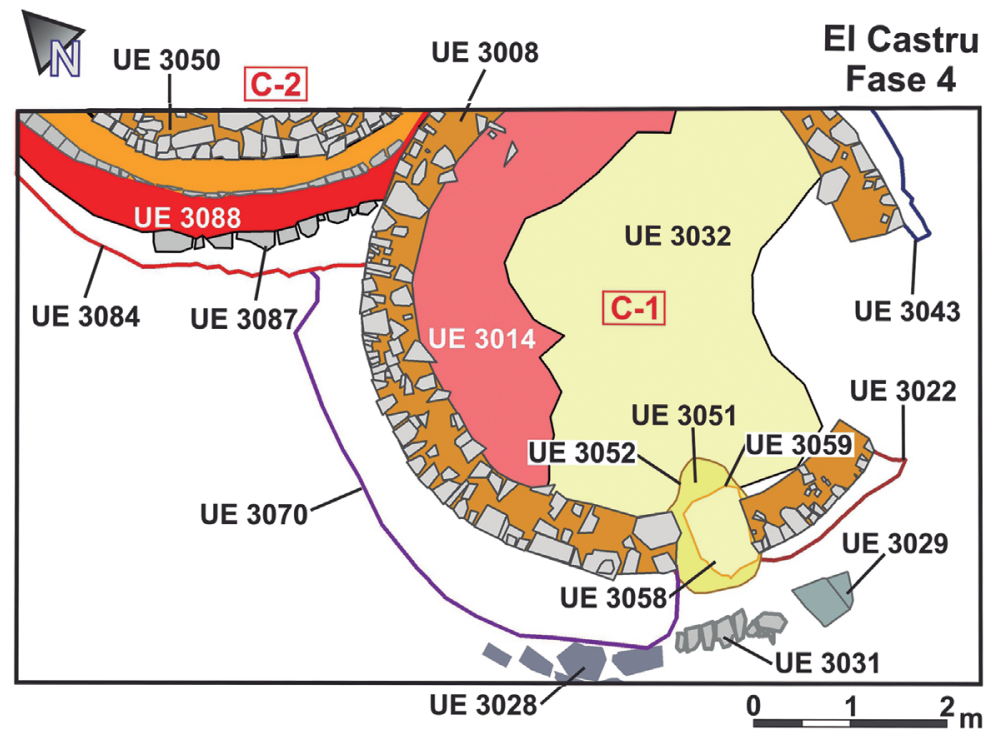

Fig. 12. Planimetría de la Fase 4, relacionada con la construcción y uso de las cabañas C-1 y C-2. / Plan of the Phase 4 , which comprises the construction and occupation of huts C-1 and C-2.

en relación con esta cabaña se documentaron una serie de unidades constructivas frente al umbral de la puerta-que ofrece una orientación hacia el Sur-Suroeste- cuya función no ha podido ser esclarecida debido a su posición marginal en el área intervenida. Se trata de los bloques pétreos UEs 3028 y 3029 de grandes dimensiones que flanquean la entrada, junto al murete UE 3031 (Fig.13b). Por su parte, el estrato UE 3030 de matriz arcillosa funcionaría como un nivel de tránsito en su entrada al exterior de la cabaña.

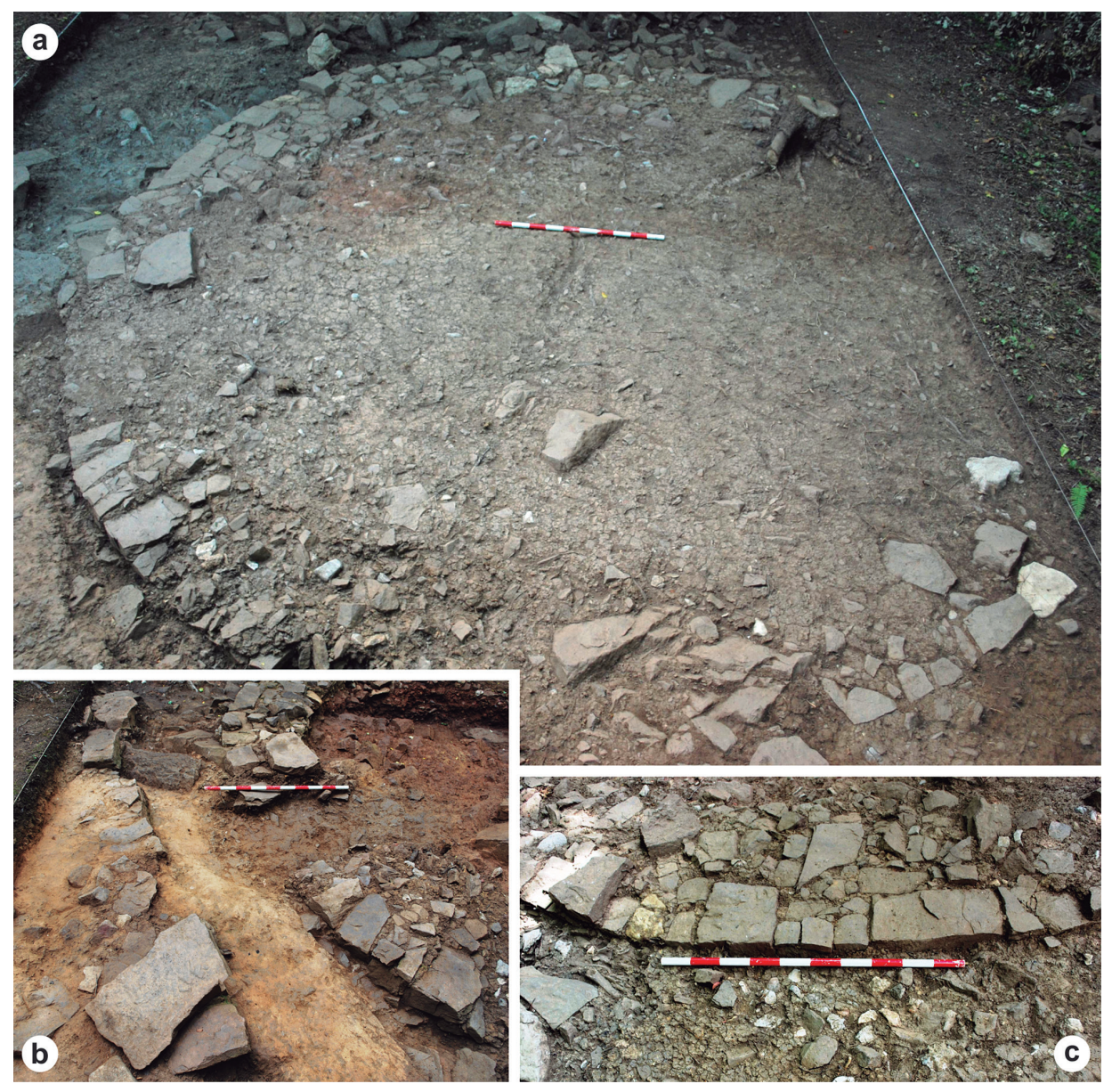

Fig. 13. Vista en planta de la cabaña C-1 durante la retirada de la UE 3006 de cronología contemporánea (a). Detalle de las estructuras reconocidas frente al umbral de C-1 en paralelo a su zócalo, con los bloques pétreos UE 3029 en primer término, seguidos del murete UE 3031 y los bloques UE 3029, además del hoyo UE 3051 excavado justo bajo la entrada antes de erigir el zócalo UE 3008 (b). Detalle del paramento UE 3008 que define el zócalo de C-1, con el nivel UE 3015 al exterior, definido por la acumulación de pequeños cantos de caliza de color blanquecino (c) / View of hut C-1 during the excavation of layer 3006 , with a contemporary chronology (a). Detailed view of the structures that were recognized in front of the entrance to hut $\mathrm{C}-1$ in parallel to its wall (stone blocks 3029, small wall 3031, and stone blocks 3029, at the forefront of the picture). and the hole 3051, that was dug before the construction of the wall 3008 , right below the entrance of the hut (b). Close view to the wall 3008 that defines the hut C-1, showing the layer 3015 in the exterior, where an accumulation of small size white limestone rolling stones were found (c). 
La cabaña C-2 muestra una morfología constructiva similar a la de $\mathrm{C}-1$, aunque el trazado conservado es mínimo dentro del área excavada. Por ello, sólo se documentó la testa del muro/zócalo UE 3050 que la define, así como su zanja exterior de cimentación. La unidad constructiva describe un trazado curvo que lleva a esta construcción a casi adosarse a la cabaña C-1. El zócalo fue levantado con sillarejo de cuarcitas de mediano tamaño del que se conservan hasta ocho hiladas, siendo difícil discernir si se trata de un zócalo similar al de la cabaña C-1, o si parte de la estructura muraria se elevaría sobre la rasante del suelo (Fig.14a). Al examinar su alzado se advierten dos escalones sucesivos en la cara externa, con un primer reborde en su tramo inferior asimilable a una zapata basal de cimentación; mientras que a mitad de su alzado un segundo reborde podría señalar el tránsito hacia una hipotética sección aérea de la pared de la cabaña. Tal consideración cobra sentido al valorar que esa cota coincide con el techo de los estratos que rellenan la zanja de cimentación UE 3084 creada para instalar la cabaña.

El estudio de las relaciones estratigráficas entre las zanjas de cimentación de ambas cabañas y sus rellenos permite aseverar que la cabaña $\mathrm{C}-1$ fue construida con anterioridad a la cabaña C-2. La excavación de la zanja de cimentación UE 3084 de C-2 cortó los rellenos más profundos de la zanja de cimentación UE 3070 de $\mathrm{C}-1$, a la vez que los estratos que rellenan la zanja UE
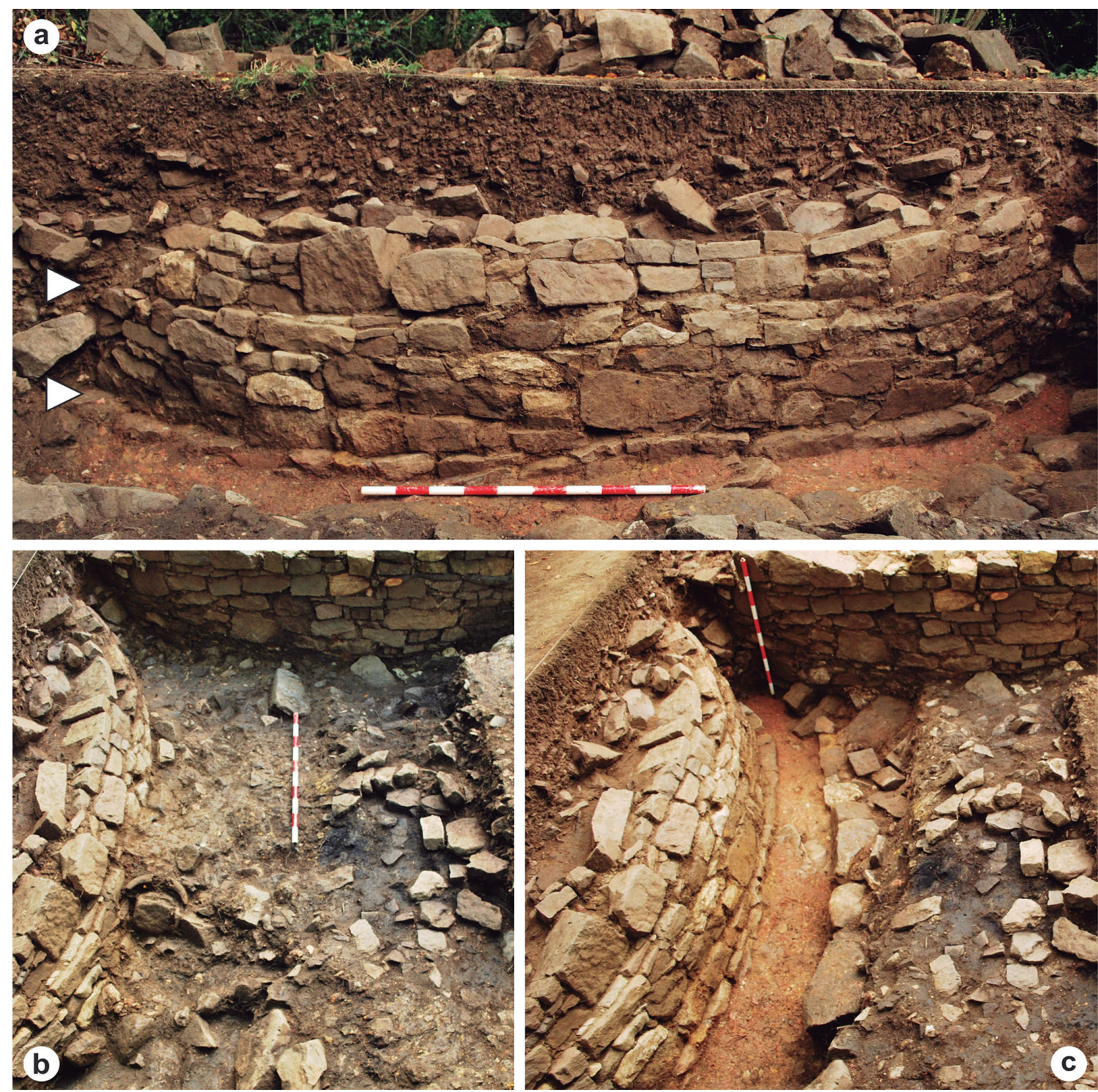

Fig. 14. Vista del alzado de la UE 3050 que define la cabaña C-2 con indicación de los sucesivos escalones en su cara que marcarían una zapata basal y el hipotético tránsito a la sección aérea de la estructura (a). Vista del proceso de excavación de los rellenos alojados en la zanja UE 3084 (b y c), hasta dejar visto el nivel de arcillas rojizas UE 3088 y la hilada de bloques UE 3087 (c). / View of the wall 3050 which defines hut C-2, showing the small steps that mark the basal footing and the hypothetical change to the aerial section of the wall (a). View of the excavation process of the deposits contained by the foundation ditch 3084 (b and c), until the red clay of layer 3088 was exposed in addition to the aligned stones 3087 (c). 
DAVID GONZÁLEZ ÁLVAREZ, CARLOS MARÍN SUÁREZ, CARLOTTA FARCI, PABLO LÓPEZ GÓMEZ, JOSÉ ANTONIO LÓPEZ-SÁEZ, CANDELA MARTÍNEZ BARRIO, MARCOS MARTINÓN-TORRES, ANDRÉS MENÉNDEZ BLANCO, MARTA MORENO-GARCÍA, SARA NÚÑEZ DE LA FUENTE, LEONOR PEÑA-CHOCARRO, GUILLEM PÉREZ-JORDÁ, JESÚS RODRÍGUEZ-HERNÁNDEZ, CARLOS TEJERIZO GARCÍA, MARGARITA FERNÁNDEZ MIER

3084 de C-2 se apoyan en el lienzo exterior del zócalo de C-1 (Fig.14b). No obstante, se observan relaciones de contemporaneidad en el uso del espacio exterior a ambas cabañas, por lo que se puede afirmar que las dos cabañas estuvieron habitadas sincrónicamente durante la fase 4 .

La zanja UE 3084 acomodó el zócalo de la cabaña C-2 en la esquina norte de la cata, cortando distintos estratos pertenecientes a las fases 1, 2 y 3 hasta alcanzar la roca madre, cuya profundidad aumenta en esta zona debido a la pendiente del terreno. Por ello, sus constructores colocaron a soga sobre la roca madre una hilada de piedras calizas (UE 3087) para sostener la pared vertical de la zanja. Instalado dicho murete, la zanja fue sellada con sucesivos niveles de arcillas (UEs 3089, 3090 y 3088) con la probable intención de impermeabilizar su fondo, destacando el llamativo tono rojizo del relleno UE 3088 (Fig. 14C). Sobre estos niveles se depositaron posteriormente otros tres niveles de rellenos de mayor porte (UEs 3080, 3085 y 3057). Completada la construcción de la cabaña C-2, se instaló la plataforma UE 3049 en el espacio exterior que esta estructura comparte con la inmediata cabaña C-1. Esta plataforma, compuesta por sillarejos de mediano y gran tamaño trabados con arcilla anaranjada, se adosa a los zócalos de ambas cabañas para generar un nivel de tránsito y otorgar mayor consistencia al terreno. Sobre ella aparece el nivel de tránsito UE 3073 coetáneo al uso de ambas cabañas.

En la amplia extensión de la cabaña C-1 fueron reconocidas tres zanjas de cimentación (UEs 3022, 3042 y 3070) que alojaron el zócalo UE 3008 de la estructura. Su trazado se individualiza en distintos tramos interrumpidos por la entrada a la cabaña y un afloramiento rocoso que sustituye por completo al zócalo en la esquina este de la cata. De hecho, las hendiduras de este cres- tón muestran arcilla amarillenta similar al recubrimiento UE 3016, regularizando así la superficie del crestón para sostener el alzado de la cabaña. Entre las zanjas excavadas para cimentar C-1, la UE 3070 es la unidad que contiene más información, con una anchura variable que alcanza los $70 \mathrm{~cm}$ hacia el exterior del zócalo. Dicha zanja fue colmatada por los rellenos UEs 3075, 3068, 3067 y 3035, pertenecientes a distintos momentos de las fases 4 y 5 , durante las cuales esta construcción mantendría su vigencia. Asimismo, bajo la entrada abierta al Suroeste de C-1 se reconocen dos hoyos sucesivos excavados de forma previa a la erección del zócalo. El hoyo UE 3052 es el más reciente y más amplio, está rellenado por la UE 3051 y cubre a su vez un primer hoyo UE 3059 más profundo y de menores dimensiones, rellenado por la UE 3058. En ambos se recuperaron abundantes restos de fauna y varios cantos de piedra depositados en el borde del hoyo más profundo.

\subsubsection{Fase 5}

Esta fase incluye diferentes estratos relacionados con el colapso y amortización de la muralla y el posterior uso del cuadrante noroccidental del área excavada al exterior de la cabaña C-1. Junto a materiales cerámicos asimilables a la Segunda Edad del Hierro, estos contextos aportaron algunas piezas de cronología altoimperial romana, acotando el final de esta fase, que se corresponde con el último momento habitacional reconocido hasta el momento en El Castru.

En el área exterior al Oeste de C-1, la UE 3015 forma un nivel de tránsito caracterizado por el acondicionamiento de su sección superior con pequeños cantos blanquecinos de caliza. El estrato rodea dicha cabaña cubriendo la zanja de cimentación UE 3070. De

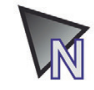

\section{El Castru Fase 5}

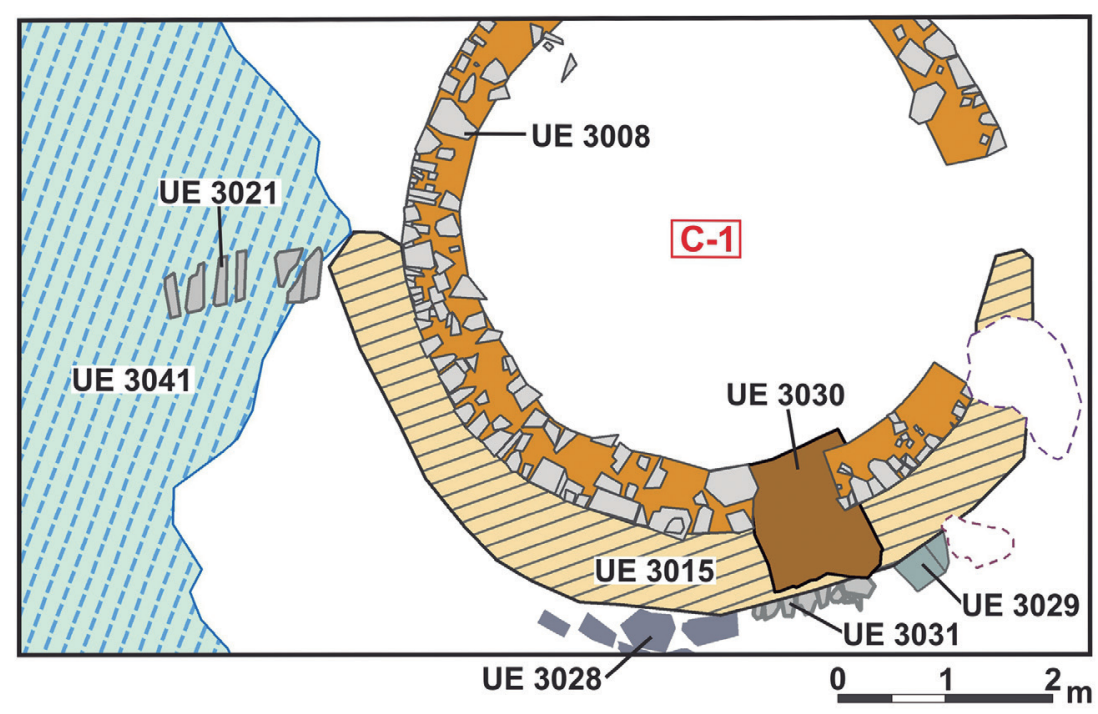

Fig. 15. Planimetría de la Fase 5, ligada a los niveles de tránsito posteriores al colapso de la muralla. / Plan of the Phase 5, with the use soils later than the collapse of the wall. 
apariencia similar y funcionamiento equivalente a la UE 3015, la UE 3041 se adapta y regulariza las variaciones en la cota preexistente del terreno sobre las estructuras metalúrgicas ya amortizadas de la fase 3 , así como la muralla entonces ya desmantelada (Fig.15). Relacionado con este horizonte, se reconoció un murete de piedras calizas UE 3021 sobre el derrumbe de la muralla que contribuía a regularizar esta zona. En esta fase se incluye también el estrato UE 3056 que rellena una concavidad entre las cubetas metalúrgicas de la fase 3 y el alzado de la muralla en la esquina oeste del área exca- vada, y regulariza la superficie sobre la que se instala la UE 3041. Durante la excavación de todos estos niveles se recuperó gran cantidad de materiales, entre los que destacan unos pocos fragmentos de cerámica común romana de cronología altoimperial y piezas de cocción reductora con decoraciones de líneas bruñidas características de la Segunda Edad del Hierro (Marín Suárez 2012) (Figs.16-17). Estos estratos contenían asimismo una gran cantidad de restos arqueozoológicos relacionables con despojos del consumo doméstico o del procesado de los animales sacrificados.

\section{Fase 3}

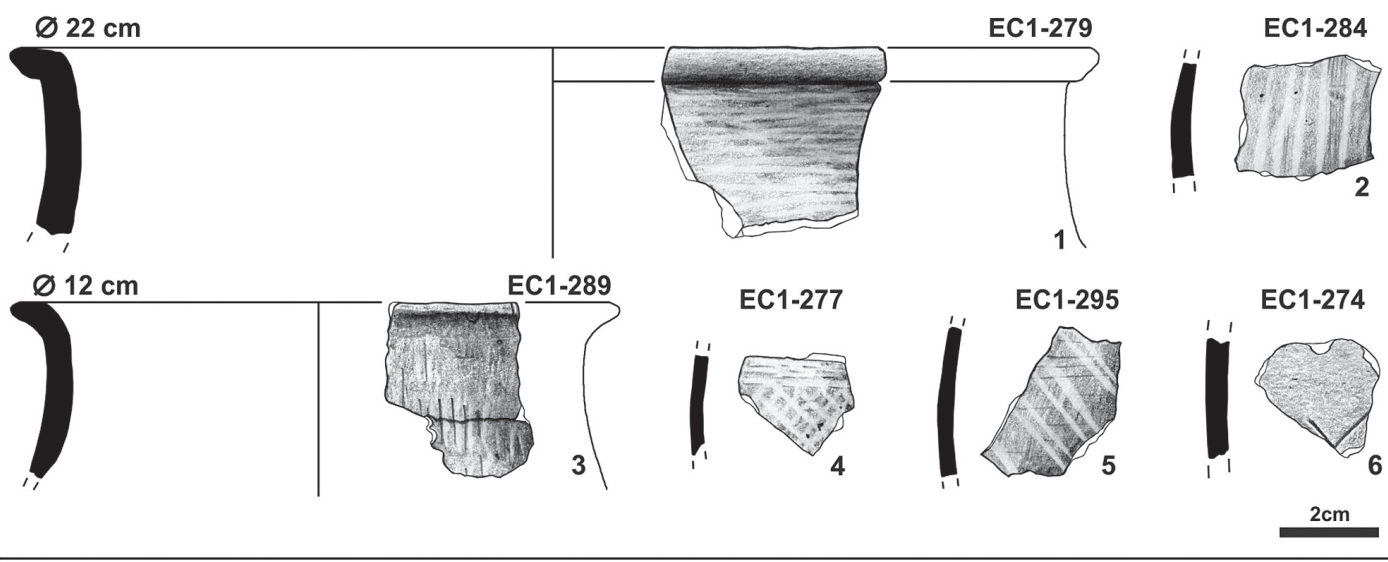

\section{Fase 4}
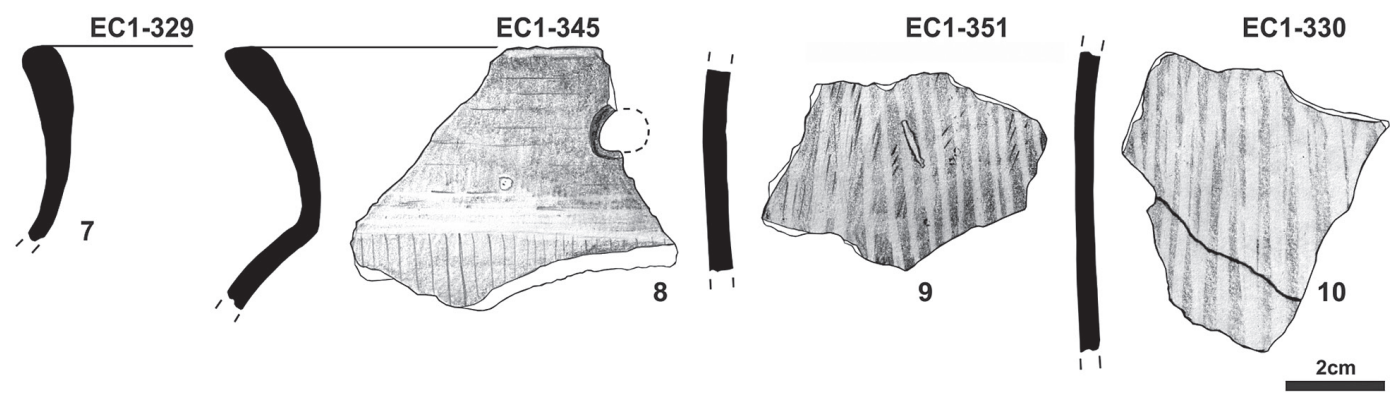

\section{Fase 5}
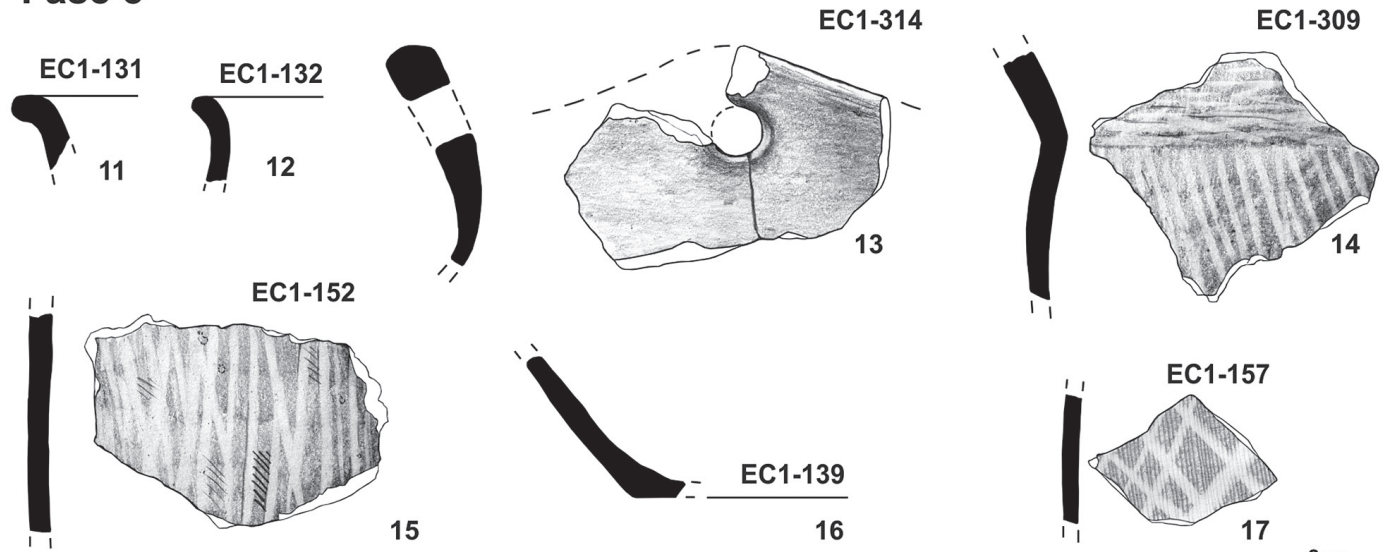

Fig. 16. Cerámica de la CTO prerromana de la Segunda Edad del Hierro. Fase 3: UE 3011 (1-6); Fase 4: UE $3057(7,10)$, UE 3085 (8-9); Fase 5: UE $3015(11-12$ 15-17), UE 3026 (13), ÜE 3020 (14). / Late Iron Age pottery (pre-Roman CTO) Phase 3: layer 3011 (1-6): Phase 4: layer 3057 (7, 10), layer 3085 (8-9): Phase 5: layer $3015 \quad(11-12$ 15-17), layer 3026

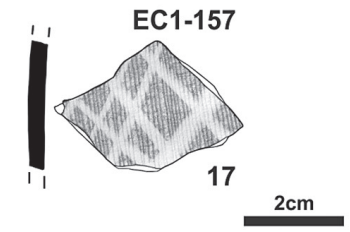

(13), layer 3020 (14). 
DAVID GONZÁLEZ ÁLVAREZ, CARLOS MARÍN SUÁREZ, CARLOTTA FARCI, PABLO LÓPEZ GÓMEZ, JOSÉ ANTONIO LÓPEZ-SÁEZ, CANDELA MARTÍNEZ BARRIO, MARCOS MARTINÓN-TORRES, ANDRÉS MENÉNDEZ BLANCO, MARTA MORENO-GARCÍA, SARA NÚÑEZ DE LA FUENTE, LEONOR PEÑA-CHOCARRO, GUILLEM PÉREZ-JORDÁ, JESÚS RODRÍGUEZ-HERNÁNDEZ, CARLOS TEJERIZO GARCÍA, MARGARITA FERNÁNDEZ MIER

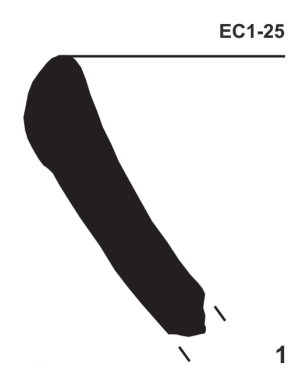

$\varnothing 33 \mathrm{~cm}$

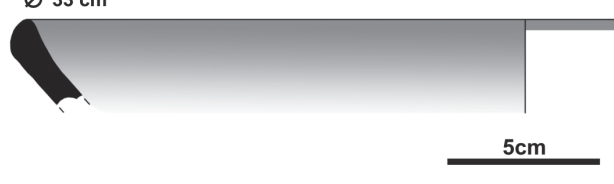

Bajo los anteriores niveles, se identificó un gran derrumbe formado por dos estratos. El primer estrato (UE 3020) lo componen bloques de gran tamaño, muchos de ellos careados, al Noroeste de la cabaña C-1. Entre la esquina norte y el espacio donde confluyen las cabañas C-1 y C-2 la entidad de los bloques aumenta en la sección inferior del derrumbe (individualizada como UE 3026), con grandes sillarejos en una matriz arcillosa anaranjada y más plástica. Si bien muchos de estos bloques muestran un buzamiento Suroeste-Noreste homólogo al estrato UE 3020, otros se disponen de manera más bien horizontal. Ello nos hizo pensar que ambos niveles formarían un mismo paquete de derrumbe, siendo la UE 3026 su primera colada. En definitiva, contemplaríamos un derrumbe masivo procedente del desmantelamiento o colapso de la muralla localizada en la esquina oeste de la cata. Cabe advertir que el derrumbe no sobrepasa en su extensión el zócalo de la cabaña C-1, mientras que cubría por completo la testa del muro de la cabaña C-2. De ello se desprende que esta última cabaña estaría amortizada en el momento de producirse este derrumbe, al contrario que la primera.
EC1-319

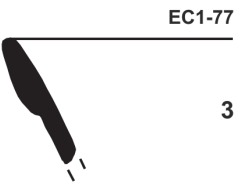

Fig. 17. Cerámicas romanas de El Castru. 1-2: CTO "común romana" de la UE 3002 (fase 6): 3: Posible borde de terra sigillata recuperado en la UE 3003 (fase 6); 4: Plato "imitación de rojo pompeyano" de la CTO 2 hallado a techo de la UE 3041 (fase 5). / Roman pottery from El Castru. 1-2: Roman common ware CTO from layer 3002 (Phase 6); 3: possible terra sigillata rim from layer 3003 (Phase 6); 4: plate fragment of Pompeian red slipe ware imitation (CTO 2) found in the upper section of layer 3041 (Phase 5).

\subsubsection{Fase 6}

Los niveles relacionados con cultivos subactuales (UEs 3001 y 3002), con abundante presencia de materia orgánica, cierran la secuencia. También se identifican en esta fase unidades relacionadas con la ruina y la amortización del poblado (UEs 3004, 3006 y 3040) afectadas por las labores agrarias desarrolladas en la última centuria. Estos estratos contienen materiales modernos como vidrios, cerámicas vidriadas y lozas contemporáneas, junto a materiales residuales de fases previas. La acción reciente del arado y la azada afectaron a los horizontes más altos en la secuencia estratigráfica y generaron desplazamientos de elementos constructivos de la cabaña $\mathrm{C}-1$, creando paquetes como las UEs 3034 y 3039 (Fig.18). Estas afecciones, junto a la erosión en ladera posterior al abandono del poblado, habrían arrasado los niveles interiores de uso de la cabaña C-1, no identificándose estratos interpuestos entre las UEs 3006, 3034 y 3039 y los rellenos de nivelación de dicha estructura correspondientes a la fase 4 de la secuencia. Además, en esta fase se reco-
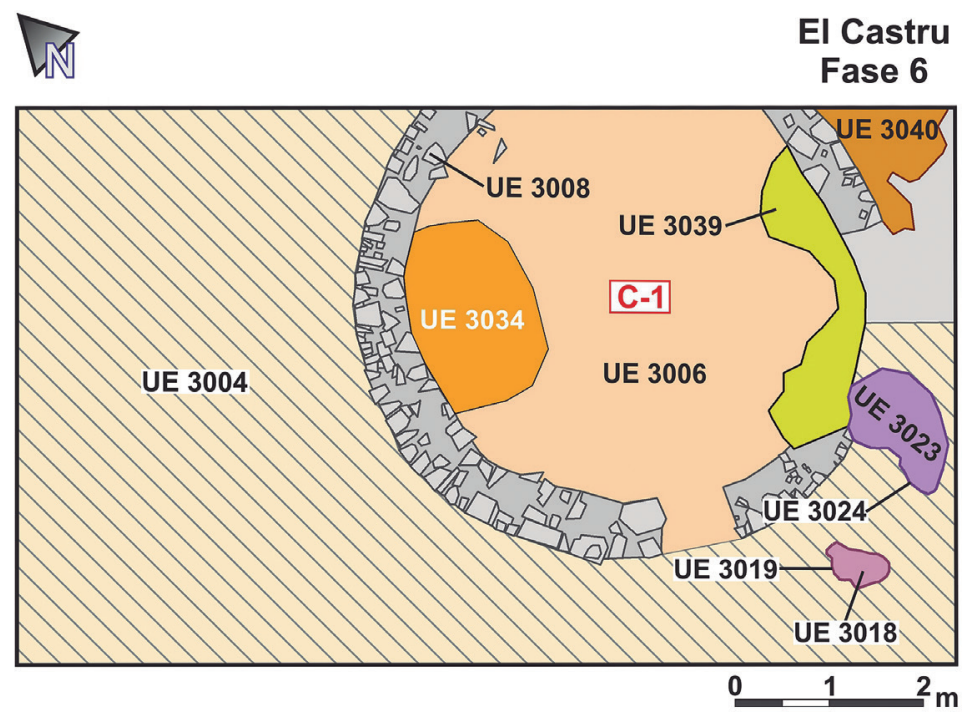

\section{El Castru \\ Fase 6}

Fig. 18. Planimetría de la Fase 6 de cronología contemporánea. / Plan of the Phase 6 from Contemporary period 
nocen hoyos (UEs 3019 y 3024) de finalidad incierta y cronología contemporánea, considerando los materiales presentes en sus rellenos.

\section{LOS ESPACIOS DOMÉSTICOS}

Las excavaciones de El Castru han permitido reconocer parcialmente tres construcciones domésticas correspondientes con las fases 1 y $4 / 5$ de su secuencia cronoestratigráfica. Su estudio arquitectónico reviste gran interés, pues llena vacíos informativos preexistentes en esta área geográfica (Ayán Vila 2012; Marín Suárez 2011: 299-307, 427-441; Villa Valdés 2008). No obstante, la reducida extensión explorada y las afecciones derivadas del uso recurrente del espacio limitan el alcance del análisis.

La estructura C-3 de la Fase 1 de El Castru es una cabaña de planta alargada correspondiente a la Fase Ic de la secuencia de la Edad del Hierro en el área occidental cantábrica (Jordá-Pardo et al. 2009). En concordancia con paralelos disponibles para la Primera Edad del Hierro en esta región como las cabañas parcialmente publicadas de El Castillo de San Martín (Carrocera y Camino 1996: 60), la construcción estaría levantada con postes de madera que sostendrían una cubierta con techumbre vegetal. Las paredes estarían formadas probablemente por entretejidos vegetales recubiertos de barro o elementos de tapial, con ciertos segmentos del alzado enlucidos en color blanco. El suelo interior estaría uniformizado con arcilla apisonada.

Por su parte, las cabañas C-1 y C-2 fueron construidas en un momento entre los siglos IV-III cal a.C., dentro de la fase 4 de la secuencia de El Castru, en la fase lla de la secuencia de la Edad del Hierro en el occidente cantábrico (Jordá-Pardo et al. 2009). Comparten una planta circular definida por muros/zócalos construidos en mampostería con bloques de cuarcita trabados con argamasa amarillenta cuidadosamente colocados. Estas piezas habrían sido extraídas de los frentes rocosos de la ladera oriental del poblado. Las unidades constructivas de ambas cabañas se asientan sobre el nivel basal de la roca madre, a través de zanjas de cimentación. Sus zócalos soportarían los postes lígneos y las paredes de materiales perecederos que formarían el alzado. Las dos construcciones muestran así unas características formales similares, aunque su apariencia externa sería ligeramente diferente: la cabaña C-2 tendría un pequeño tramo de pared de mampostería, mientras el alzado de C-1 estaría compuesto completamente por materiales perecederos. No obstante, sus caracteres arquitectónicos encajan bien con los rasgos de cabañas de la Segunda Edad del Hierro de castros próximos como La Campa Torres (Maya y Cuesta 2001: 55-57, 85-88), El Castiellu de Llagú (Berrocal-Rangel et al. 2002: 120-137), El Picu Castiellu de Moriyón (Camino 1997: 60-78) o La Garba (Fanjul Peraza et al. 2007: 72-73).

En relación con estas dos cabañas se recuperaron evidencias interesantes para explorar el componente social y simbólico de sus procesos constructivos. Por un lado, bajo el vano de la entrada abierta al mediodía de la cabaña $\mathrm{C}-1$ se reconoció el conjunto ya descrito con dos hoyos sucesivos excavados en el sustrato de arcillas naturales. Su excavación deparó como hallazgos reseñables la presencia de dos cantos de piedra cuidadosamente dispuestos sobre el fondo del hoyo más profundo, mientras que entre los restos óseos recuperados (108 restos en el relleno UE 3051 y 5 en el nivel UE 3058) no aparecieron deposiciones en conexión anatómica, siendo en su mayor parte restos de vacuno o elementos indeterminados de macromamíferos. No obstante, la situación bajo la entrada de la cabaña de estas evidencias denota una acción consciente relacionada con el proceso constructivo, marcando quizá la localización precisa para la entrada a la nueva casa.

Más reveladores resultan los hallazgos recuperados en los rellenos de la zanja de cimentación de la cabaña C-2. Como exponíamos previamente, la instalación de esta cabaña en la zona norte del área excavada demandó cierto cuidado al ser un terreno inestable en ladera. Alzada la unidad muraria UE 3050, sus constructores rellenaron el fondo de la zanja con delgadas capas arcillosas selladas a su vez por otra capa uniforme de arcillas (UE 3088) de un vivo color rojo. Sobre este nivel se depositaron una escápula derecha de cerdo, un fragmento proximal de radio de vacuno y un fragmento distal de tibia de vacuno, los dos últimos con mordeduras de perro. A continuación, el primer relleno vertido fue la UE 3080 de tierra grisácea y bloques pétreos de mediano tamaño, que generó una potente bolsada que crece desde el fondo de la zanja apoyándose contra el zócalo UE 3050. Las piedras de su núcleo fueron colocadas con cuidado contra el muro, recuperándose en su matriz un total de 399 restos de fauna. Dentro del conjunto se identificó una concentración en la parte alta del estrato, bajo los bloques de mayor tamaño, con restos de ovicaprinos y vacuno. Dicha concentración apareció coronada por un gran bloque cúbico de piedra sobre el que los constructores de la casa colocaron cuidadosamente dos cuernos de carnero, de tal modo que el mencionado bloque podría pasar por ser la cabeza del animal (Fig.19). Posteriormente, en la misma zanja se depositaron los rellenos UEs 3085 y 3057 en los que también se recuperaron abundantes fragmentos óseos (718 y 637 restos, respectivamente). La parte alta del nivel UE 3057 aportó dos objetos singulares próximos al bloque tocado con los cuernos de carnero: un fragmento de asta trabajado como enmangue y un cuchillo de hierro afalcatado aún enmangado.

Las evidencias descritas señalan la existencia de factores en la construcción de estas cabañas que superan los parámetros formales de un mero proceso constructivo. Concuerdan con ciertos paralelos reconocibles en castros del entorno, como los depósitos de cerámicas estampilladas en niveles fundacionales de viviendas de la Segunda Edad del Hierro en San L!̣uis 
DAVID GONZÁLEZ ÁLVAREZ, CARLOS MARÍN SUÁREZ, CARLOTTA FARCI, PABLO LÓPEZ GÓMEZ, JOSÉ ANTONIO LÓPEZ-SÁEZ,
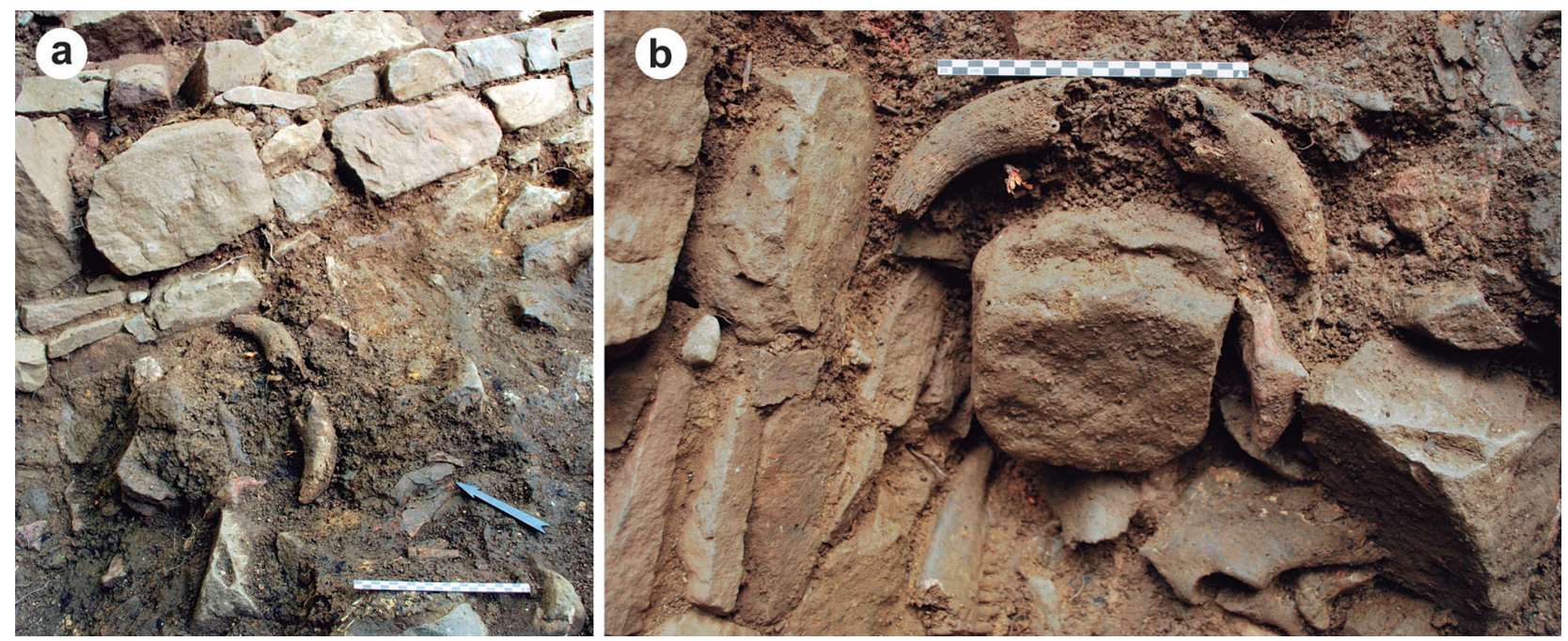

Fig. 19. Depósito hallado en la zanja de cimentación de C-2. / Deposit found in the foundation ditch for the hut C-2.

(Marín Suárez 2007: 154, 2011: 444), el hacha de talón y anillas hallada bajo un hogar en otra cabaña de la misma época en El Chao Samartín (De Blas Cortina y Villa Valdés 2007), el puñal de antenas identificado como depósito fundacional de la construcción C-3 del poblado de Os Castros en Taramundi (Villa Valdés et al. 2007: 269), o los enterramientos de perinatales y de un cordero bajo el pavimento de la cabaña denominada «estructura 05» de La Peña del Castro de La Ercina (González Gómez De Agüero et al. 2015: 196). El protagonismo de un carnero y su vinculación con un cuchillo de hierro afalcatado en el depósito vinculado a C-2 en El Castru tiende conexiones además con relaciones semejantes reconocidas en el interior peninsular (Cabrera Díez y Moreno-García 2014). En definitiva, este tipo de depósitos estructurados abren una ventana al contexto social y simbólico que rodearía el levantamiento de una nueva cabaña, actividad que implicaría la participación colaborativa de la comunidad. Podemos imaginar que, en paralelo al levantamiento de las paredes o del techado de la nueva vivienda, tendrían lugar acciones rituales que pautarían diferentes etapas del proceso constructivo, con depósitos votivos, ceremonias y/o banquetes. Estos eventos sancionarían el proceso constructivo, protegerían quizá el devenir de la vida familiar en la nueva casa, fortaleciendo los lazos de reciprocidad del conjunto de familias que vivían en El Castru.

\section{FORMAS DE SUBSISTENCIA}

El estudio de las formas de subsistencia de las comunidades de la Edad del Hierro es quizá la línea de investigación que requiere una revisión y actualización más urgente de los conocimientos disponibles para el área occidental cantábrica. Estos temas han recibido escasa atención, a menudo por las limitantes condiciones de conservación de los elementos arqueobiológicos, aunque también por la ausencia de especialistas en los equipos investigadores, o incluso el desinterés por estos aspectos (González Álvarez 2016: 353). La buena conservación de los restos arqueobiológicos en El Castru, junto a la clara apuesta por la interdisciplinariedad en la estrategia investigadora implementada, ofrecen un buen soporte para abordar este tipo de cuestiones. Los estudios arqueobiológicos o el análisis del entorno del poblado sientan las bases para una lectura más profunda de las formas de vida adoptadas por las gentes que habitaron El Castru a lo largo de la Edad del Hierro y comienzos de época romana, tal y como podemos anticipar a partir de diversos estudios aún en marcha.

\subsection{La cabaña ganadera}

La colección arqueofaunística recuperada en El Castru comprende un total de 11.953 restos óseos, de los cuales un $30 \%$ fueron identificados a nivel de especie (Tabla 2). Las condiciones edafológicas y el tipo de depósitos que conforman los contextos arqueológicos en los que fueron desechados estos materiales condicionan los altos índices de fragmentación registrados. Todas las fases de la secuencia muestran una proporción de restos no determinados que se sitúa en torno al $70 \%$. Tal hecho afecta en mayor grado a los elementos más frágiles, como los cráneos, así como a los restos óseos menos robustos de especies de menor tamaño como los caprinos.

La abundante muestra de restos de vacuno, caprinos y cerdo, además de la presencia testimonial de équidos, contrasta con la escasa representación de recursos cinegéticos (ciervo, corzo y jabalí). Esto revela el papel predominante de las cabañas ganaderas en la economía de este asentamiento castreño de montaña. La contribución del ganado vacuno oscila entre un $42 \%$ en la fase 3 y un 59\% en la fase 5. Le siguen en importancia los caprinos y el cerdo, que ocupan la segunda y tercera posición, respectivamente, si exceptuamos la 


\begin{tabular}{|c|c|c|c|c|c|}
\hline FASE & NR & $\% \mathrm{~N}$ & \%DOM & NMEm & $\%$ NMEm \\
\hline $\begin{array}{l}1 \\
\text { Caballo } \\
\text { Vacuno } \\
\text { Oveja/Cabra } \\
\text { [Cabra] } \\
\text { [Oveja] } \\
\text { Jabalí/Cerdo } \\
\text { Ciervo } \\
\text { Corzo } \\
\text { Total determinado } \\
\text { Total no determinado } \\
\text { Aves } \\
\text { Piscis } \\
\text { TOTAL }\end{array}$ & $\begin{array}{c}- \\
55 \\
31 \\
{[1]} \\
{[4]} \\
104 \\
- \\
- \\
190 \\
344 \\
- \\
- \\
534\end{array}$ & $\begin{array}{c}19,5 \\
- \\
- \\
35,5 \\
64,5 \\
- \\
- \\
100\end{array}$ & $\begin{array}{c}- \\
29 \\
16\end{array}$ & $\begin{array}{c}- \\
17 \\
8\end{array}$ & $\begin{array}{c}- \\
44 \\
19\end{array}$ \\
\hline $\begin{array}{l}2 \\
\text { Caballo } \\
\text { Vacuno } \\
\text { Oveja/Cabra } \\
\text { [Cabra] } \\
\text { [Oveja] } \\
\text { Jabalí/Cerdo } \\
\text { Ciervo } \\
\text { Corzo } \\
\text { Total determinado } \\
\text { Total no determinado } \\
\text { Aves } \\
\text { Piscis } \\
\text { TOTAL }\end{array}$ & $\begin{array}{c}1 \\
106 \\
75 \\
- \\
{[26]} \\
108 \\
- \\
- \\
290 \\
613 \\
- \\
- \\
903\end{array}$ & $\begin{array}{c}<1 \\
12 \\
8 \\
\\
12 \\
- \\
- \\
32 \\
68 \\
- \\
- \\
100\end{array}$ & $\begin{array}{l}37 \\
26\end{array}$ & $\begin{array}{l}25 \\
18\end{array}$ & $\begin{array}{l}45 \\
33 \\
22\end{array}$ \\
\hline $\begin{array}{l}3 \\
\text { Caballo } \\
\text { Vacuno } \\
\text { Oveja/Cabra } \\
\text { [Cabra] } \\
\text { [Oveja] } \\
\text { Jabalí/Cerdo } \\
\text { Ciervo } \\
\text { Corzo } \\
\text { Total determinado } \\
\text { Total no determinado } \\
\text { Aves } \\
\text { Piscis } \\
\text { TOTAL }\end{array}$ & $\begin{array}{c}3 \\
466 \\
460 \\
{[37]} \\
{[110]} \\
366 \\
7 \\
2 \\
1304 \\
3363 \\
2 \\
2 \\
4671\end{array}$ & $\begin{array}{c}8 \\
<1 \\
<1 \\
28 \\
72 \\
<1 \\
<1 \\
100\end{array}$ & $\begin{array}{l}36 \\
36\end{array}$ & $\begin{array}{l}96 \\
80\end{array}$ & $\begin{array}{l}42 \\
35\end{array}$ \\
\hline
\end{tabular}

\begin{tabular}{|c|c|c|c|c|c|}
\hline FASE & NR & $\% \mathrm{~N}$ & \%DOM & NMEm & \%NMEm \\
\hline $\begin{array}{l}4 \\
\text { Caballo } \\
\text { Vacuno } \\
\text { Oveja/Cabra } \\
\text { [Cabra] } \\
\text { [Oveja] } \\
\text { Jabalí/Cerdo } \\
\text { Ciervo } \\
\text { Corzo } \\
\text { Total determinado } \\
\text { Total no determinado } \\
\text { Aves } \\
\text { Piscis } \\
\text { TOTAL }\end{array}$ & $\begin{array}{c}6 \\
301 \\
215 \\
{[19]} \\
{[66]} \\
125 \\
1 \\
- \\
648 \\
1413 \\
- \\
- \\
\mathbf{2 0 6 1}\end{array}$ & $\begin{array}{c}6 \\
<1 \\
32 \\
68 \\
- \\
- \\
\mathbf{1 0 0}\end{array}$ & $\begin{array}{l}47 \\
34 \\
19\end{array}$ & $\begin{array}{l}59 \\
35 \\
\\
21\end{array}$ & $\begin{array}{l}51 \\
31 \\
\\
18\end{array}$ \\
\hline $\begin{array}{l}\mathbf{5} \\
\text { Caballo } \\
\text { Vacuno } \\
\text { Oveja/Cabra } \\
\text { [Cabra] } \\
\text { [Oveja] } \\
\text { Jabali/Cerdo } \\
\text { Ciervo } \\
\text { Corzo } \\
\text { Total determinado } \\
\text { Total no determinado } \\
\text { Aves } \\
\text { Piscis } \\
\text { TOTAL }\end{array}$ & $\begin{array}{c}- \\
602 \\
189 \\
{[16]} \\
{[34]} \\
220 \\
6 \\
1 \\
1018 \\
2332 \\
- \\
- \\
\mathbf{3 3 5 0}\end{array}$ & $\begin{array}{c}- \\
18 \\
6 \\
\\
7 \\
<1 \\
<1 \\
30 \\
70 \\
- \\
- \\
100\end{array}$ & $\begin{array}{l}59 \\
19 \\
\\
22\end{array}$ & $\begin{array}{l}98 \\
36 \\
30\end{array}$ & $\begin{array}{r}59 \\
22 \\
\\
19\end{array}$ \\
\hline $\begin{array}{l}6 \\
\text { Caballo } \\
\text { Vacuno } \\
\text { Oveja/Cabra } \\
\text { [Cabra] } \\
\text { [Oveja] } \\
\text { Jabalí/Cerdo } \\
\text { Ciervo } \\
\text { Corzo } \\
\text { Total determinado } \\
\text { Total no determinado } \\
\text { Aves } \\
\text { Piscis } \\
\text { TOTAL }\end{array}$ & $\begin{array}{c}- \\
71 \\
27 \\
{[2]} \\
- \\
25 \\
2 \\
- \\
125 \\
311 \\
- \\
- \\
\mathbf{4 3 6}\end{array}$ & $\begin{array}{c}6 \\
<1 \\
- \\
29 \\
71 \\
- \\
- \\
\mathbf{1 0 0}\end{array}$ & & & \\
\hline
\end{tabular}

Tabla 2: Restos arqueozoológicos recuperados en El Castru, Vigaña. Relación y frecuencia (\%NR) del número de restos faunísticos (NR) analizados. Frecuencia de las principales cabañas domésticas según el NR identificado (\%DOM), el número mínimo de elementos ponderado de acuerdo con el número de elementos presentes en un esqueleto (NMEm) y su frecuencia relativa (\%NMEm). Este último valor corrige la suprarepresentación de los taxones con mayor número de restos o más fragmentados. El NMEm no incluye cuernos/astas, fragmentos de cráneo, incisivos, caninos, vértebras (exceptuando atlas y axis) ni costillas, de ahí que sea un valor inferior al NR. Los materiales de la Fase 6 al ser de cronología reciente no se evalúan. / Zooarchaeological remains recovered in El Castru hillfort, Vigaña. Relation and frequency $(\% N R)$ in the number of faunal remains (NR) that were analised. Frequency of the main domestic anima herds according to the identified NR (\%DOM), the minimum number of elements weighed according to the number of elements present in a skeleton (NMEm) and their relative frequenzy (\%NMEm). This last value corrects the overrepresentation of those species with higher amount of remains or showing a higher fragmentation. The NMEm does not include horns/antlers, skull fragments, incisors, canine teeth, vertebrae (with the exception of atlae and axises and second cervical vertebrae), nor ribs. This makes NMEm lower than NR. The remains from Phase 6 were not analised, considering their recent chronology.

fase 1 en la que el ganado porcino supera al lanar. Se cumple de esta manera la tendencia observada durante la Edad del Hierro en otros yacimientos del área occidental cantábrica (Albizuri 2001; Liesau y García García 2005; Morales Muñiz y Liesau 1994), confirmándose la importancia de los bóvidos para estas comunidades antes de la romanización.

El análisis de las edades de sacrificio sugiere un uso diversificado de las vacas y los caprinos, entre los que dominan las ovejas frente a las cabras. La presencia de individuos jóvenes y sub-adultos junto a otros seniles indica el aprovechamiento de reses de ganado vacuno que han alcanzado un peso óptimo, y que en el caso de las hembras habrían podido criar al menos una vez. También refleja el aprovechamiento de la fuerza de estos animales para el trabajo agrario, hasta el límite de su supervivencia. En el ganado porcino el alto número identificado de hembras adultas implica una inversión en la crianza local de esta especie destinada a cubrir una parte importante de las necesidades dietéticas de carne y grasa.

Por su parte, los perfiles anatómicos apuntan al procesamiento y consumo in situ de las carcasas, aunque se observa una abundancia mayor del esqueleto craneal (representado por una enorme cantidad de dientes sobre todo en las fases 3, 4 y 5) frente al apendicular y axial, quizás resultado de la conservación diferencial y los procesos diagenéticos indicados. En 
DAVID GONZÁLEZ ÁLVAREZ, CARLOS MARÍN SUÁREZ, CARLOTTA FARCI, PABLO LÓPEZ GÓMEZ, JOSÉ ANTONIO LÓPEZ-SÁEZ,

este sentido, cabe reseñar la presencia generalizada sobre los restos óseos de marcas de dientes y mordidos efectuadas probablemente por perros, especie doméstica cuya presencia se manifiesta igualmente a través la conservación de algunos coprolitos.

En resumen, los resultados preliminares indican la existencia de comunidades de subsistencia bien adaptadas al medio, cuyas bases económicas recaerían en la gestión ganadera vinculada a la actividad agraria y la obtención de productos secundarios como la leche y la lana, circunstancias que condicionarían en cierta medida sus hábitos dietéticos en lo referente al consumo cárnico.

\subsection{Los restos carpológicos}

En las 19 muestras de sedimento flotadas en el yacimiento de El Castru se recuperaron un total de 59 restos de semillas y frutos en diversos estratos de cuatro fases de ocupación diferentes (Tabla 3). Los únicos taxones cultivados son los cereales, documentándose la cebada vestida (Hordeum vulgare subsp. vulgare), los trigos desnudos (Triticum aestivum-durum), la escanda (Triticum dicoccum) y el panizo (Setaria italica). No se ha constatado la presencia de leguminosas y el único fruto conservado (Prunus sp.) debe ser un fruto silvestre recolectado. El resto de los taxones presentes son plantas silvestres que crecen como malas hierbas entre los campos de cereales o en el entorno de las áreas ocupadas por las comunidades humanas (Avena sp., Fallopia convolvulus, Galium aparine, Plantago sp, etc). El escaso registro presenta similitudes con lo que se conoce en otros asentamientos de las comunidades castreñas del Noroeste ibérico y área occidental cantábrica (Camino 1997; López-Merino et al. 2010; Teira Brión 2010; Tereso et al. 2013), y reflejaría un sistema agrícola centrado en la producción de distintos cereales -y en menor medida de leguminosas- en el que la arboricultura no se habría desarrollado aún.

\begin{tabular}{|c|c|c|c|c|c|c|c|c|c|c|}
\hline & \multicolumn{4}{|c|}{ FASE 1} & \multicolumn{3}{|c|}{ FASE 2} & \multicolumn{2}{|c|}{ FASE 3} & \multirow{2}{*}{$\begin{array}{c}\text { FASE } 4 \\
3051\end{array}$} \\
\hline & 3048 & 3098 & 3091 & 3097 & 3054 & 3066 & 3076 & 3009 & 3064 & \\
\hline \multicolumn{11}{|l|}{ CEREALES } \\
\hline Hordeum vulgare subsp. vulgare & & & & & & & 1 & 1 & 1 & 1 \\
\hline Hordeum vulgare & & & & 1 & & & & 1 & 1 & \\
\hline Setaria italica & & & 1 & & & 1 & & 3 & 1 & 1 \\
\hline Setaria itálica gluma & & & & & & & & 1 & & \\
\hline Triticum aestivum-durum & 1 & 1 & & & 2 & 3 & & 3 & & 1 \\
\hline Triticum $s p$. & & & & & 3 & 4 & & 3 & & \\
\hline Triticum dicoccum & & & & & 1 & & & 2 & & \\
\hline Triticum dicoccum espiguilla & & & & & & 3 & & & & \\
\hline Hordeum/Triticum frag. & & & & & & 6 & & 3 & & \\
\hline \multicolumn{11}{|l|}{ FRUTOS } \\
\hline Prunus sp. & & & & & & 6 & & 3 & & \\
\hline \multicolumn{11}{|l|}{ PLANTAS SILVESTRES } \\
\hline Avena sp. & & 1 & & & & & & & & \\
\hline Atriplex sp. & & & & & & & & 1 & & \\
\hline Chenopodium sp. actual? & & & & 1 & & & & 3 & & \\
\hline Ciperacea & & & & & & & & 1 & & \\
\hline Fallopia convulvulus & & & & & 1 & & & 2 & & \\
\hline Galium aparine & & & & & 1 & & & & & \\
\hline \multicolumn{11}{|l|}{ Leguminosa pequeña } \\
\hline Plantago sp. & & & & & & & & 1 & & \\
\hline Rubiacea & & & & & & 1 & & 1 & & \\
\hline Rumex sp. & & 1 & & & & & & & & \\
\hline \multicolumn{11}{|l|}{ Sclerotia } \\
\hline Indeterminada & & & 1 & & 3 & & & 2 & & \\
\hline $\mathrm{n}^{\circ}$ restos: & 1 & 3 & 2 & 2 & 11 & 18 & 1 & 29 & 3 & 3 \\
\hline $\mathrm{n}^{\circ}$ taxones: & 1 & 3 & 1 & 2 & 5 & 6 & 1 & 15 & 3 & 3 \\
\hline
\end{tabular}

Tabla 3: Seeds recovered in El Castru hillfort. / Restos carpológicos recuperados en El Castru. 


\subsection{Análisis palinológico}

Cuatro muestras de sedimentos (10 g) para análisis polínicos fueron tomadas en la secuencia de la zona alta de El Castru, dos de la fase 1 (UEs 3048 y 3098) y otras dos de la fase 4 (UEs 3058 y 3051). Éstas fueron tratadas según el protocolo usual en estudios arqueopalinológicos (Burjachs et al. 2003), estableciéndose los morfotipos polínicos de acuerdo a Moore et al. (1991); mientras que el morfotipo Cerealia se identificó siguiendo a Beug (2004). Los microfósiles no polínicos fueron identificados según López-Sáez et al. (1998), aceptando para su validación las directrices estadísticas y tafonómicas expuestas en López-Sáez et al. (2013; 2003).

El histograma palinológico (Fig.20) de El Castru demuestra la presencia de una cobertura arbórea relativamente densa durante toda la Edad de Hierro, más importante en la fase 1 (63-65\%) que en la fase 4 (56-59\%). El taxón arbóreo más importante es Quercus pyrenaica/robur, reflejando la existencia de un denso robledal de roble carballo acidófilo en el piso colino de la zona de estudio durante la fase 1 (29-30\%). Esta formación arbórea aparece más degradada en la fase 4 (17-18\%), cuando otros árboles heliófilos y pioneros como el abedul (Betula; 11-12\%) o el avellano (Corylus; $6-9 \%)$ cobran mayor relevancia, al igual que ciertos elementos propios de las etapas seriales degradativas de estos bosques, caso de los brezales de Erica arborea $(6-6,5 \%)$ y los helechares de Pteridium aquilinum (4,5-6\%). Aunque en ambas fases se documentan evidencias de antropización del medio, éstas son más reseñables en la fase 4, cuando tanto las herbáceas antrópicas-nitrófilas (12-13\% en la fase 1 a 21-22\% en la fase 4) como las antropozoógenas incrementan sus valores. Lo cual parece relacionarse con una presión pastoral más importante en la fase 4, cuando los hongos coprófilos arrojan valores más elevados (16-18\%) que en la fase 1 (5\%) (López-Sáez y López-Merino 2007). En las cuatro muestras estudiadas se documenta polen de Cerealia, en porcentajes suficientes (3\%) para admitir la existencia de cultivos agrícolas en la inmediatez del yacimiento (López-Sáez y López-Merino 2005).

\section{LA PRODUCCIÓN METALÚRGICA EN EL CASTRU}

Las actividades metalúrgicas documentadas en la fase 3 constituyen un capítulo destacado en la secuencia del yacimiento, como ya se comentó anteriormente. El análisis de 29 fragmentos de crisol proporciona una interesante lectura de los procesos metalúrgicos desarrollados en la Segunda Edad del Hierro por los habitantes de El Castru (Farci et al. 2017). El estudio de la tecnología empleada para la producción de las aleaciones de cobre y el papel de los crisoles en las actividades metalúrgicas han constituido los objetivos centrales de la investigación desarrollada. En particular, se estudiaron las concreciones y adherencias metálicas presentes en los crisoles, así como las escorias y piezas metálicas, para discernir las posibles prácticas metalúrgicas presentes en la fase 3 de El Castru.

Su estudio conllevó primero una evaluación y documentación visual del conjunto, centrándose en la caracterización general de la fábrica de los crisoles y en la presencia de residuos. La aplicación de fluorescencia de rayos-x por medio de un equipo portátil (pXRF) com-

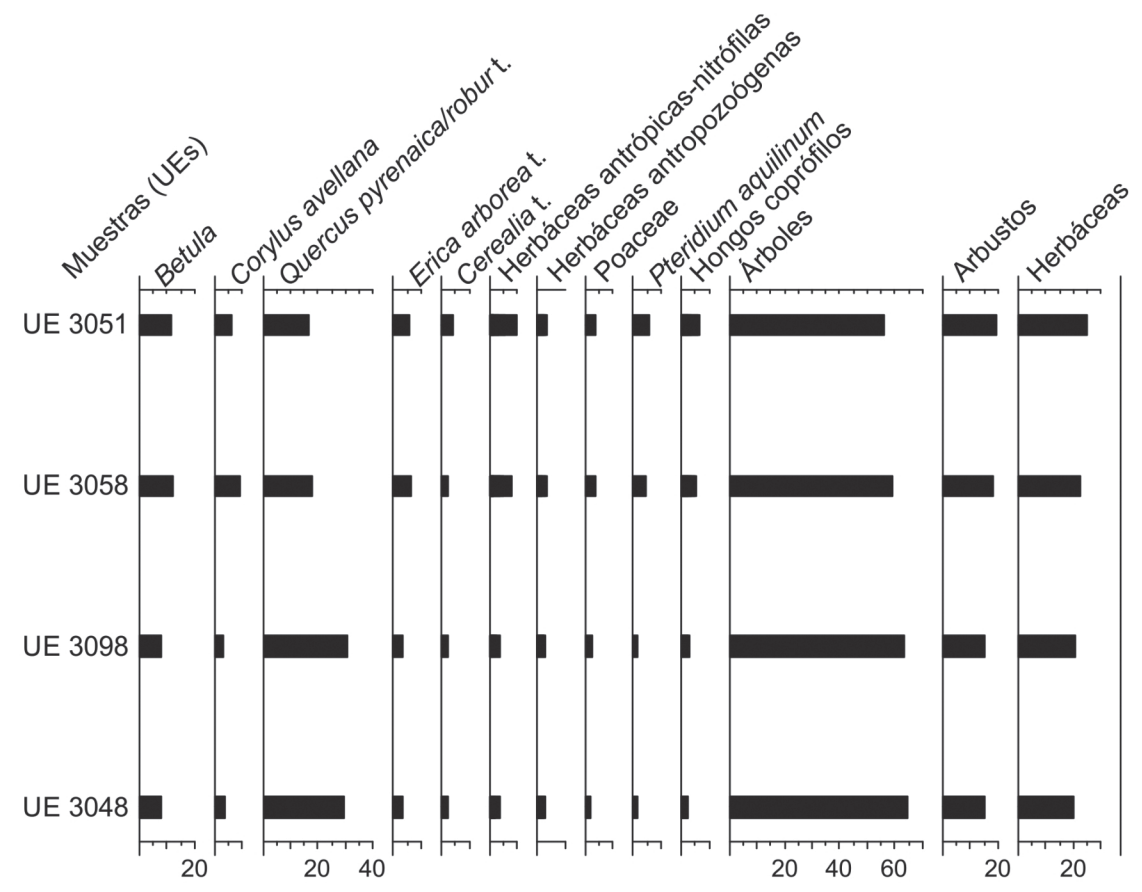

Fig. 20. Histograma palinológico de las muestras analizadas en EI Castru obtenido mediante los programas TILIA y TGView. / Palynological historgram with the pollen samples analysed from El Castru, obtained using TILIA and TGView software programs. 
DAVID GONZÁLEZ ÁLVAREZ, CARLOS MARÍN SUÁREZ, CARLOTTA FARCI, PABLO LÓPEZ GÓMEZ, JOSÉ ANTONIO LÓPEZ-SÁEZ, CANDELA MARTÍNEZ BARRIO, MARCOS MARTINÓN-TORRES, ANDRÉS MENÉNDEZ BLANCO, MARTA MORENO-GARCÍA, SARA NÚÑEZ DE LA FUENTE, LEONOR PEÑA-CHOCARRO, GUILLEM PÉREZ-JORDÁ, JESÚS RODRÍGUEZ-HERNÁNDEZ, CARLOS TEJERIZO GARCÍA, MARGARITA FERNÁNDEZ MIER

pletó el examen macroscópico, revelando la presencia extendida de cobre, estaño y plomo en las caras internas y externas de los crisoles, que habrían sido utilizados para la obtención de bronce. Posteriormente, se examinó una selección de fragmentos de crisol, así como de pequeños trozos de escorias, a través de láminas delgadas, utilizando para ello microscopía óptica y un microscopio electrónico de barrido con energía espectométrica dispersiva (SEM-EDS).

La mayoría de los fragmentos de crisol fueron realizados a mano utilizando para ello una fina arcilla blanquecina, aunque unas pocas piezas tienen pastas oscuras con la inclusión de desgrasantes gruesos. Los fragmentos recuperados provienen de piezas relativamente pequeñas con formas predominantemente abiertas que serían calentadas desde el interior, como evidencia la presencia de carbones en el interior de los recipientes. Basándonos en los análisis realizados, podemos clasificar las muestras en tres grupos funcionales y proponer así una reconstrucción de las técnicas metalúrgicas y materiales empleados en El Castru. De este modo, podemos concluir que entre los trabajos metalúrgicos no-férricos identificados en la fase 3 de la secuencia se incluyen la producción directa de aleaciones de bronce, muy probablemente por la cementación de casiterita con cobre metálico; la fundición de chatarra de bronce o pequeños lingotes; así como la obtención de bronce a través de la fundición conjunta de minerales de bronce y estaño. La comparación con casos similares en otros castros del área occidental cantábrica como La Campa Torres (Rovira Llorens y Gómez Ramos 2001) refuerza la impresión de que estas actividades metalúrgicas fueron realizadas a pequeña escala por artesanos locales que trabajarían en talleres del propio asentamiento, donde la metalurgia con crisoles seguía una tradición regional milenaria.

Futuros estudios servirán de ayuda para reconocer las posibles conexiones del taller metalúrgico de $\mathrm{El}$ Castru con actividades semejantes en otros castros del entorno, así como para determinar las áreas de captación de minerales que alimentaron esta actividad artesanal y sus vinculaciones con las pautas territoriales de estas comunidades. Otros temas pendientes de consideración, a partir de nuevos análisis y del estudio de nuevas colecciones, serían si los crisoles constituyen en la Edad del Hierro del Noroeste ibérico productos manufacturados por especialistas a escala regional, o si estas piezas fueron fabricadas localmente compartiendo similares formas y materiales; además de explorar la validez de la diferenciación funcional tradicionalmente establecida en los yacimientos ibéricos para los diferentes tipos de crisoles.

\section{VALORACIÓN DE LOS RESULTADOS}

Las excavaciones efectuadas en El Castru muestran una secuencia de ocupación que arranca en la Primera Edad del Hierro con la construcción de una mu- ralla perimetral en mampostería (fase 0 de la secuencia cronoestratigráfica) en un momento por precisar de las fases lb o lc del fenómeno castreño en el área occidental cantábrica (Jordá-Pardo et al. 2009). Configurado el sistema defensivo, se establecieron estructuras domésticas con materiales perecederos en el interior del recinto (fase 1). Posteriormente, se suceden dos horizontes datados en la Segunda Edad del Hierro caracterizados por el desarrollo de actividades artesanales. En la primera de ellas (fase 2) no se ha podido concretar la naturaleza de tales labores, mientras que la segunda (fase 3) ofrece evidencias de trabajos metalúrgicos para la producción de bronce. A continuación, se individualiza una etapa (fase 4) en la que se construyen cabañas a partir del siglo IV-III cal a.C. que amortizan la referida zona metalúrgica. Algunas de estas construcciones estarían habitadas hasta momentos posteriores al desmantelamiento de la muralla castreña (fase 5), ya en las primeras décadas de la época altoimperial romana. Es entonces cuando se abandona el poblado. La secuencia del yacimiento concluye con niveles agrarios de época contemporánea (fase 6).

La comunidad que habitó El Castru a lo largo de la Edad del Hierro desarrolló un régimen de vida marcado por la autosuficiencia. El trabajo agrícola y ganadero colmaría las necesidades subsistenciales de sus habitantes, siendo la caza y la recolección actividades complementarias, aunque marginales; necesidades como la producción metalúrgica, cerámica o textil estarían cubiertas a escala del poblado. Las excavaciones no han identificado materiales alóctonos que pudiesen derivar de intercambios a larga distancia, salvo los contados fragmentos de cerámica común romana de su última etapa. Cabe considerar, por tanto, una fuerte cohesión comunitaria en sus habitantes, cuyos referentes identitarios más robustos serían la propia comunidad, indisociable del poblado monumentalizado que construyen, reconstruyen y, en definitiva, habitan.

Las gentes que vivieron en este poblado a partir de la Primera Edad del Hierro desarrollaron un modelo agrario basado en la complementariedad entre la agricultura y la ganadería. En su entorno inmediato establecerían un mosaico de campos con aprovechamientos agrícolas diversos en los que cultivarían diferentes tipos de cereales de verano e invierno, con variedades desnudas y vestidas, mientras otros terrenos alimentaban sus rebaños domésticos. Los limitados datos carpológicos no respaldan lecturas suficientemente detalladas para advertir cambios diacrónicos en las especies empleadas, matices que sí soporta la colección de restos arqueozoológicos. Estos datos muestran una tendencia progresiva hacia la especialización ganadera en torno a la cabaña vacuna. Los rebaños de los habitantes de El Castru estarían mayoritariamente conformados en la Segunda Edad del Hierro por reses de ganado vacuno, en probable relación con modelos de pastoreo con movilidad vertical que aprovecharían los diferentes ecotopos accesibles en torno a esta aldea monumentalizada 
en función de las significativas diferencias altitudinales del entorno. El impacto de las actividades agrarias en los espacios próximos al poblado, así como una tendencia hacia una antropización más intensiva en la Segunda Edad del Hierro, son rasgos también observables en los datos polínicos. Por su parte, actividades como la recolección de frutos silvestres, la caza o la pesca fluvial completarían el régimen subsistencial de estas gentes, aunque su peso sería limitado, probablemente ligado a momentos puntuales del ciclo estacional con gran disponibilidad de estos recursos.

El Castru se convirtió en una aldea monumentalizada gracias a la selección de un enclave destacado en su entorno y a la construcción de elementos defensivos que realzaron su prominencia en el paisaje circundante. La conducción de estas obras y su mantenimiento a lo largo del tiempo serían así un esfuerzo colectivo que materializaba la unidad social, política y económica del grupo. Frente a las tradicionales interpretaciones jerárquicas de las sociedades castreñas del área cantábrica (Torres Martínez 2011), el dispositivo defensivo/ monumental podría ser considerado una inversión de esfuerzo que reforzó los lazos intracomunitarios de la población de El Castru mediante la experiencia constructiva en sí misma (Parcero Oubiña 2005). Este dispositivo defensivo visibilizaría hacia afuera la identidad compartida de sus habitantes, monumentalizando la fortaleza en términos sociales y políticos del agregado poblacional local, confrontándolo con las colectividades castreñas de su entorno. Tal y como han manifestado diversos autores (González García et al. 2011; González Ruibal 2006-2007; Marín Suárez 2011; Sastre Prats 2008), la asunción de este código explícitamente relacionado con la guerra alejaría las tensiones internas de la comunidad hacia el exterior, enfatizando un enfrentamiento más retórico que real respecto a las comunidades vecinas (González García 2009). Esa aparente isonomía hacia adentro de las pequeñas comunidades castreñas escondería no obstante una creciente desigualdad de género que se consolidaría paralela a la creciente relevancia social y simbólica del hombre guerrero (Marín Suárez 2011). Este proceso conformaría un paisaje social fragmentado, donde las tensiones sociales y políticas más agudas se producirían entre las comunidades vecinas, que vivían en castros de tamaños y contingentes poblacionales similares (González Álvarez 2016). Lo cual concuerda con el proceso de progresiva humanización del entorno de estos poblados que, como demuestran los datos paleoambientales y arqueobiológicos de El Castru, asistirían a una progresiva antropización ligada a la extensión de las actividades agrarias.

\section{AGRADECIMIENTOS}

La excavación de El Castru se enmarca en los proyectos de investigación «La formación de los paisajes del Noroeste peninsular durante la Edad Media (Siglos
V-XII)» (Ref. HAR2010-21950-C03-03) y «Poder central y poderes locales entre la Antigüedad Tardía y la Alta Edad Media, 400-900 d.C. El Norte de Hispania y su contexto europeo» (Ref. HAR2013-47889-C3-3-P). La intervención fue posible gracias a la generosidad de Javier Menéndez Rivera y Mariano Álvarez García, propietarios de los terrenos explorados.

\section{CONTRIBUCIÓN DE LOS AUTORES}

DGA y CMS coordinaron la excavación e interpretación del yacimiento, proceso al que contribuyeron como técnicos PLG, CMB, AMB, JRH y CTG. CF y MMT realizaron el estudio arqueometalúrgico; JALS y SNF examinaron las muestras palinológicas; MMG estudió los restos arqueozoológicos; LPC y GPJ analizaron las evidencias carpológicas. MFM dirige los proyectos marco en los que se desarrolló esta actuación. DGA diseñó la estructura del artículo y lideró su redacción, contribuyendo todos los autores a la revisión de sucesivos borradores y a su discusión final.

\section{BIBLIOGRAFÍA}

Albizuri, S., 2001. Estudio Arqueozoológico de los mamíferos salvajes y domésticos de La Campa Torres (Gijón): estrato de los siglos II y I a.C. In: Maya, J.L., Cuesta, F. (Eds.), El castro de La Campa Torres. Período prerromano, 317-347. VTP, Gijón.

Ayán Vila, X.M., 2012. Casa, Familia y Comunidad en la Edad del Hierro del NW. Universidade de Santiago de Compostela, Tesis Doctoral.

Berrocal-Rangel, L., Martínez Seco, P., Ruiz Triviño, C., 2002. El Castiellu de Llagú (Latores, Oviedo). Un castro astur en los orígenes de Oviedo. Real Academia de la Historia, Madrid.

Beug, H.-J., 2004. Leitfaden der Pollenbestimmung für Mittleleuropa und angrenzende Gebeite. Gustav Fisher Verlag, Stuttgart.

Blas Cortina, M.A. de, Villa Valdés, A., 2007. La presencia no accidental de un hacha de talón en un fondo de hogar en el castro del Chao Samartín (Grandas de Salime, Asturias). In: Celis, J., Delibes, G., Fernández Manzano, J., Grau, L. (Eds.), El hallazgo leonés de Valdevimbre y los depósitos del Bronce final atlántico en la península ibérica, 280-289. Junta de Castilla y León, León.

Bronk-Ramsey, C.B., Lee, S., 2013. Recent and Planned Developments of the Program OxCal. Radiocarbon 55(2-3), 720-730.

Burjachs, F., López-Sáez, J.A., Iriarte, M.J., 2003. Metodología Arqueopalinológica. In: Buxó, R., Piqué, R. (Eds.), La recogida de muestras en Arqueobotánica: objetivos y propuestas metodológicas, 11-18. Museu d'Arqueologia de Catalunya, Barcelona.

Cabrera Díez, A., Moreno-García, M., 2014. Prácticas de sacrificio en el Cerro de La Mesa (Alcolea de Tajo, Toledo): el depósito ritual de la casa 1. Zephyrus 73, 133-147.

Camino, J., 1997. Excavaciones en los castros de la ría de Villaviciosa. Cuadernos de Cubera 9, 43-86.

Camino, J., Estrada, R., Viniegra, Y., 2009. El castro inacabado de La Forca (Grado, Asturias). Un dominio territorial frustrado. Trabajos de Prehistoria 66(1), 145-159. 
DAVID GONZÁLEZ ÁLVAREZ, CARLOS MARÍN SUÁREZ, CARLOTTA FARCI, PABLO LÓPEZ GÓMEZ, JOSÉ ANTONIO LÓPEZ-SÁEZ, CANDELA MARTÍNEZ BARRIO, MARCOS MARTINÓN-TORRES, ANDRÉS MENÉNDEZ BLANCO, MARTA MORENO-GARCÍA, SARA NÚÑEZ DE LA FUENTE, LEONOR PEÑA-CHOCARRO, GUILLEM PÉREZ-JORDÁ, JESÚS RODRÍGUEZ-HERNÁNDEZ, CARLOS TEJERIZO GARCÍA, MARGARITA FERNÁNDEZ MIER

Carrocera, E., Camino, J., 1996. La Edad del Hierro en el territorio histórico de los astures o la realidad de un espacio administrativo romano. In: Fernández Ochoa, C. (Ed.), Los Finisterres Atlánticos en la Antigüedad: época romana y prerromana, 57-60. Ayto. Gijón, Madrid.

Díaz Nosty, B., Sierra Piedra, G., Blanco Vázquez, L., 1997. Inventario Arqueológico del concejo de Belmonte de Miranda. Consejería de Educación y Cultura del Principado de Asturias.

Fanjul Peraza, A., 2005. Los castros de Asturias. Una revisión territorial y funcional. Ayto. Teverga, Teverga.

Fanjul Peraza, A., Fernández Rodríguez, C., López Pérez, M.C., Álvarez Peña, A., 2007. Excavaciones en el castro de la Garba (Teverga), Asturias. Primeros trazos arqueológicos del poblamiento castreño de alta montaña. In: Fanjul Peraza, A. (Ed.), Estudios Varios de Arqueología castreña, 49-75. Ayto. Teverga, Madrid.

Fanjul Peraza, A., Fernández Rodríguez, C., López Pérez, M.C., Álvarez Peña, A., 2009. Excavaciones en los castros de La Cogollina y La Garba (Teverga). Pautas del poblamiento castreño en un valle de montaña. In: Excavaciones Arqueológicas en Asturias, 2003-2006, 465-472. Principado de Asturias, Oviedo.

Fanjul Peraza, A., Marín Suárez, C., 2006. La metalurgia del hierro en la Asturias castreña: nuevos datos y estado de la cuestión. Trabajos de Prehistoria 63(1), 113-131.

Farci, C., Martinón-Torres, M., González Álvarez, D., 2017. Bronze production in the Iron Age of the Iberian Peninsula: The case of El Castru, Vigaña (Asturias, NW Spain). Journal of Archaeological Science: Reports 11, 338-351.

Fernández Mier, M., 1999. Génesis del territorio en la Edad Media. Arqueología del paisaje y evolución histórica en la montaña asturiana. Universidad de Oviedo, Oviedo.

Fernández Mier, M., Aparicio Martínez, P., González Álvarez, D., Fernández Fernández, J., Alonso González, P., 2013. Proyecto de Investigación: La formación de los paisajes agrarios del Noroeste peninsular durante la Edad Media (siglos $\mathrm{V}$ al XII). Debates de Arqueología Medieval 3, 359-374

Fernández Mier, M., González Álvarez, D., 2013. Más allá de la aldea: Estudio diacrónico del paisaje en el entorno de Vigaña (Belmonte de Miranda). In: Excavaciones Arqueológicas en Asturias 2007-2012, 353-365. Principado de Asturias, Oviedo.

Fernández Mier, M., González Álvarez, D., Martínez Gallardo, C., López Gómez, P., Martínez Barrio, C., 2018. Nes llendes de l'aldea: Paisaxe y territoriu en Vigaña (Miranda). In: León Gasalla, P. (Coord.), Excavaciones arqueológicas en Asturias 2013-2016, 359-370. Consejería de Educación y Cultura, Principado de Asturias; Ediciones Trabe, Oviedo.

González Álvarez, D., 2009. La Cuenca del Pigüeña (Asturias) en el I milenio a.C.: poblamiento y subsistencia. Universidad Complutense de Madrid, Trabajo de Tercer Ciclo.

González Álvarez, D., 2011a. Arqueología, Folklore y comunidades locales: los castros en el medio rural asturiano. Complutum 22(1), 133-153.

González Álvarez, D., 2011b. Movilidad ganadera entre las comunidades castreñas cantábricas: el valle del Pigüeña (Asturias) como caso de estudio. In: OrJIA (Eds.), Actas de las II Jornadas de Jóvenes en Investigación Arqueológica (JIA 2009), tomo I, 147-156. Libros Pórtico, Zaragoza.

González Álvarez, D., 2016. Poblamiento y antropización de la montaña occidental cantábrica durante la Prehistoria reciente: una aproximación desde la Arqueología del Paisaje. Universidad Complutense de Madrid, Tesis doctoral.
González García, F.J., 2009. Between warriors and champions: warfare and social change in the Later Prehistory of the North-Western Iberian Peninsula. Oxford Journal of Archaeology 28(1), 59-76.

González García, F.J., Parcero Oubiña, C., Ayán Vila, X.M., 2011. Iron Age Societies against the State: An Account of the Emergence of the Iron Age in North-western Iberia. In: Moore, T., Armada, X.L. (Eds.), Atlantic Europe in the first millennium BC: Crossing the divide, 285-301. Oxford University Press, Oxford.

González Gómez de Agüero, E., Bejega García, V., Muñoz ViIlarejo, F., 2015. El poblamiento castreño en la montaña leonesa: el caso de La Peña del Castro (La Ercina, León). Férvedes 8, 191-200.

González Ruibal, A., 2006-2007. Galaicos: Poder y Comunidad en el Noroeste de la Península Ibérica (1200 a.C.-50 d.C.). Museu Arqueolóxico e Histórico Castelo de San Antón (Brigantium; 18-19), A Coruña.

Harris, E.C., 1991. Principios de Estratigrafía Arqueológica. Crítica, Barcelona.

Jordá-Pardo, J.F., Marín Suárez, C., García-Guinea, J., 2011. Discovering San Chuis Hillfort (Northern Spain): Archaeometry, Craft Technologies, and Social Interpretation. In: Moore, T., Armada, X.L. (Eds.), Atlantic Europe in the First Millennium BC. Crossing the Divide, 488-505. Oxford University Press, Oxford.

Jordá-Pardo, J.F., Rey, J., Picón, I., Abad, E., Marín Suárez, C., 2009. Radiocarbon and Chronology of the Iron Age Hillforts of Northwestern Iberia. In: Karl, R., Leskovar, J. (Eds.), Interpretierte Eisenzeiten. Fallstudien, Methoden, Theorie. Tagungsbeiträge der 3 Linzer Gespräche zur interpretativen Eisenzeitarchäologie, 69-86. Oberösterreichischen Landesmuseum, Linz.

Liesau, C., García García, J., 2005. La fauna de mamíferos del yacimiento de La Campa Torres (Gijón, Asturias, España). Zephyrus 58, 261-266.

López-Merino, L., Peña-Chocarro, L., Ruiz-Alonso, M., LópezSáez, J.A., Sánchez-Palencia, F.J., 2010. Beyond nature: The management of a productive cultural landscape in Las Médulas area (El Bierzo, León, Spain) during pre-Roman and Roman times. Plant Biosystems 144(4), 905-919.

López-Sáez, J.A., Iriarte, M.J., Burjachs, F., 2013. Arqueopalinología. In: García-Díez, M., Zapata, L. (Eds.), Métodos y Técnicas de análisis y estudio en arqueología prehistórica. De lo técnico a la reconstrucción de los grupos humanos, 269-285. Universidad del País Vasco, Bilbao.

López-Sáez, J.A., López-García, P., Burjachs, F., 2003. Arqueopalinología: síntesis crítica. Polen 12, 5-35

López-Sáez, J.A., López-Merino, L., 2005. Precisiones metodológicas acerca de los indicios paleopalinológicos de agricultura en la Prehistoria de la Península Ibérica. Portugalia, Nova Série 26, 53-64.

López-Sáez, J.A., López-Merino, L., 2007. Coprophilous fungi as a source of information of anthropic activities during the Prehistory in the Amblés Valley (Ávila, Spain): The archaeopalynological record. Revista Española de Micropaleontología 39(1-2), 103-116.

López-Sáez, J.A., van Geel, B., Farbos-Texier, S., Diot, M.F., 1998. Remarques paléoécologiques à propos de quelques palynomorphes non-polliniques provenant de sédiments quaternaires en France. Revue de Paléobiologie 17, 445-459. 
Marín Suárez, C., 2007. Los materiales del castro de San L!̣uís (Allande, Asturias). Complutum 18, 131-160.

Marín Suárez, C., 2011. De nómadas a castreños. Arqueología del primer milenio antes de la era en el sector centro-occidental cantábrico. Universidad Complutense de Madrid. Tesis Doctoral.

Marín Suárez, C., 2012. La cerámica de la Edad del Hierro en el sector centro-occidental cantábrico. Munibe. Antropologia-Arkeologia 63, 165-198.

Maya, J.L., 1989. Los castros en Asturias. Silverio Cañada Editor, Gijón

Maya, J.L., Cuesta, F., 2001. Excavaciones arqueológicas y estudio de los materiales de La Campa Torres. In: Maya, J.L., Cuesta, F. (Eds.), El castro de La Campa Torres. Período prerromano, 11-277. VTP, Gijón.

Montes López, R., Villa Valdés, A., 2018. Un asentamiento de la primera Edad del Hierro en la cuenca del Narcea: El castro de Pena Aguda (Belmonte de Miranda, Asturias). Férvedes 9, 67-74.

Moore, P.D., Webb, J.A., Collinson, M., 1991. Pollen analysis (2nd Ed). Blackwell Scientific Publications, London.

Morales Muñiz, A., Liesau, C., 1994. Los mamíferos de la factoría romana de la Plaza del Marqués (Gijón). In: Fernández Ochoa, C. (Ed.), Una industria de salazones de época romana en la Plaza del Marqués, 181-187. Ayuntamiento. Gijón, Gijón.

Parcero Oubiña, C., 2005. Variaciones en la función y el sentido de la fortificación a lo largo de la Edad del Hierro en el NO de la Península Ibérica. In: Blanco, A., Cancelo, C., Esparza, A. (Eds.), Bronce Final y Edad del Hierro en la Península Ibérica, 11-33. Universidad de Salamanca, Salamanca.

Reimer, P.J., Bard, E., Bayliss, A., Beck, J.W., Blackwell, P.G., Bronk-Ramsey, C.B., Buck, C.E., Cheng, H., Edwards, R.L., Friedrich, M., Grootes, P.M., Guilderson, T.P., Haflidason, H., Hajdas, I., Hatté, C., Heaton, T.J., Hoffmann, D.L., Hogg, A.G., Hughen, K.A., Kaiser, K.F., Kromer, B., Manning, S.W., Niu, M., Reimer, R.W., Richards, D.A., Scott, E.M., Southon, J.R., Staff, R.A., Turney, C.S.M., Van der Plicht, J., 2013. IntCal13 and Marine13 Radiocarbon Age Calibration Curves 0-50,000 Years cal BP. Radiocarbon 55(4): 1869-1887.

Rovira Llorens, S., Gómez Ramos, P. 2001. La metalurgia prerromana de La Campa Torres (Gijón, Asturias). In: Maya, J.L., Cuesta, F. (Eds.), El castro de La Campa Torres. Período prerromano, 375-384. VTP, Gijón.

Rubio Díez, R., Marcos Herrán, F.J., 2010. Aproximación al poblamiento castreño en el valle de Laciana (Villablino, León). Zephyrus 66, 181-205.

Sastre Prats, I., 2008. Community, Identity, and Conflict. Iron Age Warfare in the Iberian Northwest. Current Anthropology 49(6), 1021-1051.

Teira Brión, A.M., 2010. Tierra, metal y semillas. Consideraciones de la agricultura de la Edad del Hierro en Galicia. In: Bettencourt, A.M.S., Caetano-Alves, M.I., Monteiro-Rodrigues, S. (Eds.), Alterações Ambientais e Interacção Humana na Fachada Atlântica Occidental, 133-148. Universidade do Minho, Braga.

Tereso, J.P., Ramil-Rego, P., Álvarez González, Y., López González, L.F., Almeida-da-Silva, R., 2013. Massive storage in As Laias/O Castelo (Ourense, NW Spain) from the Late Bronze Age/Iron Age transition to the Roman period: a palaeoethnobotanical approach. Journal of Archaeological Science 40(11), 3865-3877.
Torres Martínez, J.F., 2011. El Cantábrico en la Edad del Hierro. Medio ambiente, economía, territorio y sociedad. Real Academia de la Historia, Madrid.

Villa Valdés, A., 2004. Orfebrería y testimonios metalúrgicos en el castro de Chao Samartín, Asturias (España). In: Perea, A., Montero, I., García-Vuelta, O. (Eds.), Tecnología del oro antiguo: Europa y América, 253-264. CSIC, Madrid.

Villa Valdés, A., 2007. Mil años de poblados fortificados en Asturias (siglos IX a.C.-II d.C.). In: Fernández-Tresguerres, J. (Ed.), Astures y romanos: nuevas perspectivas, 27-60. RIDEA, Oviedo.

Villa Valdés, A., 2008. La Arquitectura doméstica en los castros prerromanos. In: Rodríguez, J. (Ed.), La Prehistoria en Asturias. Un legado artístico único en el mundo, 721-752. Prensa Asturiana, Oviedo.

Villa Valdés, A., Menéndez Granda, A., Fanjul Mosteirín, J.A., 2007. Excavaciones arqueológicas en el poblado fortificado de Os Castros, en Taramundi. In: Excavaciones Arqueológicas en Asturias 2003-2006, 267-276. Principado de Asturias, Oviedo. 
